\title{
1 Serine and glycine are essential for human muscle progenitor cell population expansion
}

2 Brandon J. Gheller1, Jamie E. Blum1, Erica L. Bender1, Mary E. Gheller1, Esther W. Lim2,

3 Michal K. Handzlik2, Patrick J. Stover3, Martha S. Field1, Benjamin D. Cosgrove4, Christian M.

4 Metallo2, and Anna E. Thalacker-Mercer*1

5 1Division of Nutritional Sciences, Cornell University, Ithaca, NY, 14853, USA

6 2Department of Bioengineering, University of California San Diego, La Jolla, CA, 92093, USA

7 3College of Agriculture and Life Sciences, Texas A\&M University, College Station, TX, 77843,

8 USA

9 4Meining School of Biomedical Engineering, Cornell University, NY, 14853, USA

$10 *$ Correspondence: aet74@ cornell.edu

11

12

13

14

15

16

17

18

19

20

21

22 


\section{Summary}

Skeletal muscle regeneration is reliant on a population of muscle specific adult stem cells

26 (muscle progenitor cells; MPCs). During regeneration, the MPC population undergoes a transient

27 and rapid period of population expansion, which is necessary to repair damaged myofibers and

28 restore muscle homeostasis. Much research has focused on the age-related accumulation of

29 negative regulators of regeneration, while the age-related decline of nutrient and metabolic

30 determinants of the regenerative process needs examination. We hypothesized that older

31 individuals, a population that is at risk for protein malnutrition, have diminished availability of

32 amino acids that are necessary for MPC function. Here, we identified that levels of the non-

33 essential amino acid serine are reduced in the skeletal muscle of healthy, older individuals.

34 Furthermore, using stable-isotope tracing studies, we demonstrate that primary, human MPCs

35 (hMPCs) exhibit a limited capacity for de novo biosynthesis of serine and the closely related

36 amino acid glycine. We identified that serine and glycine are essential for $h \mathrm{MPC}$ proliferation

37 and, therefore, population expansion. Serine and glycine were necessary to support synthesis of

38 the intracellular antioxidant glutathione, and restriction of serine and glycine was sensed in an

39 EIF2 $\alpha$-dependent manner resulting in cell cycle arrest in G0/G1. In conclusion, we elucidate that,

40 despite an absolute requirement of serine/glycine for $h \mathrm{MPC}$ proliferation, availability of serine in

41 the skeletal muscle microenvironment is limited to the $h$ MPCs of healthy older adults and is a

42 likely underlying mechanism for impaired skeletal muscle regeneration with advancing age.

\section{Keywords}

44 “Satellite cell”, "Muscle stem cell," "Metabolism, "Aging," "Serine," "Glycine," "Skeletal

45 muscle" 
bioRxiv preprint doi: https://doi.org/10.1101/833798; this version posted November 7, 2019. The copyright holder for this preprint (which was not certified by peer review) is the author/funder, who has granted bioRxiv a license to display the preprint in perpetuity. It is made available under aCC-BY-NC-ND 4.0 International license.

\section{Graphical Abstract}

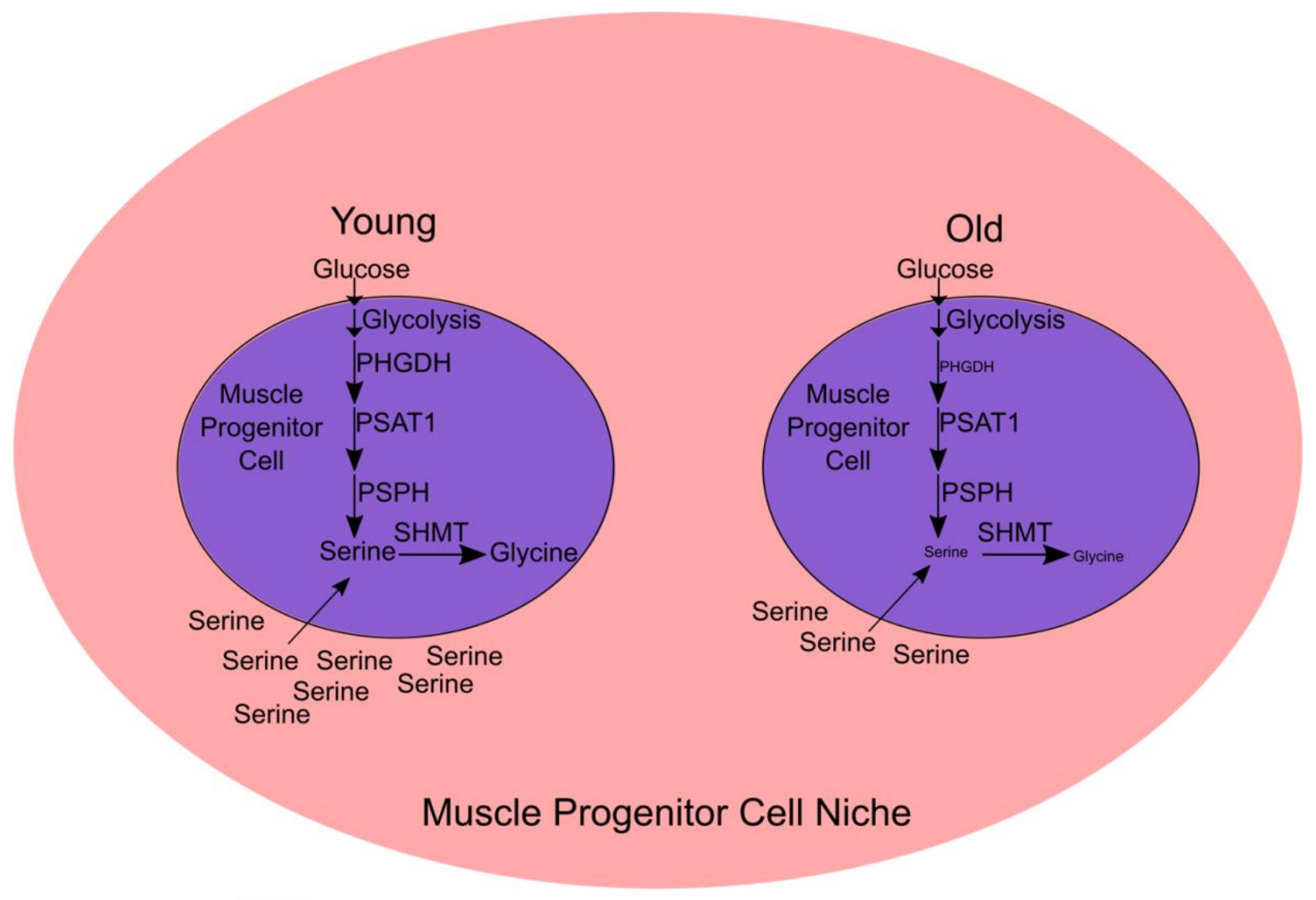




\section{Introduction}

Skeletal muscle regeneration is reliant on a population of muscle specific adult stem/ progenitor cells (MPCs) identified by the canonical transcription factor PAX7 (Seale et al., 2000). MPCs reside in a quiescent state, are activated after injury, and undergo a transient and rapid population expansion to provide an adequate number of cells to donate nuclei to damaged myofibers or to create nascent myofibers thereby restoring homeostasis. The muscle regeneration process markedly declines with age due to a myriad of MPC-intrinsic and -extrinsic factors that remain to be fully elucidated (Blau et al., 2015). Parabiosis experiments provide evidence that there are alterations in circulating factors and, ultimately the MPC microenvironment that occurs

65 in aged animals which negatively affects muscle regeneration (Conboy et al., 2005). For

66 example, when the circulation of a young and an aged mouse are joined, muscle regeneration

67 after injury is improved in old mice compared to when the circulation of two old mice are joined

68 (Conboy et al., 2005). Thus, restoration of the MPC microenvironment, to match that of young

69 animals, is a potential avenue for improving skeletal muscle regeneration (Conboy et al., 2005).

70 Follow-up to these landmark studies have largely focused on mechanisms downstream of ligand-

71 based signaling pathways such as the Notch (Conboy et al., 2003) and Wnt (Brack et al., 2007)

72 pathways as well as transforming growth factor beta pathways (Egerman et al., 2015; Sinha et

73 al., 2014). Relatively little attention has focused on nutrient needs and availability to support

74 MPC expansion. Intracellular amino acid availability has been shown to be affected by age in

75 both a cell-intrinsic (e.g., alterations in metabolism) and -extrinsic (e.g., availability in

76 circulation) manner (Dunn et al., 2014; Menni et al., 2013). For example, while gastrointestinal

77 absorption of amino acids after feeding does not appear to be impaired with age (Katsanos et al.,

78 2006; Mitchell et al., 2015), the profile of circulating amino acids is altered by age with lower 
79 levels of serine, alanine, proline, tyrosine, and methionine observed in older individuals

80 (Houtkooper et al., 2011). The importance of amino acid availability to regenerative processes is

81 highlighted by the observation that amino acids are the primary contributors to cell mass during

82 proliferation (Hosios et al., 2016).

83 It has been previously documented that rapid changes in MPC metabolism occur after

84 activation (Rodgers et al., 2014), likely to support metabolic demands associated with cell

85 division (Hosios et al., 2016). These dynamic, metabolic changes in MPCs are likely

86 accompanied by changes in exogenous nutrient requirements, particularly those traditionally

87 considered non-essential, as demonstrated in other proliferative cell types (Ma et al., 2017).

88 Elucidating the metabolic requirements of MPC proliferation is essential for optimizing muscle

89 regeneration after injury, particularly in populations with impaired regeneration.

We aimed to determine if an age-related decline in amino acid availability exists in the

91 human MPC ( $h \mathrm{MPC}$ ) microenvironment and to determine the impact of this amino acid decline

92 on MPC activity if it exists. In this study we identify that serine is the only amino acid that

93 declines in $h \mathrm{MPC}$ microenvironment with advancing age, and $h \mathrm{MPC}$ possess a limited capacity

94 for de novo biosynthesis of serine and the closely related amino acid, glycine. Without

95 exogenous serine/glycine, $h \mathrm{MPCs}$ halt proliferation and arrest in a G0/G1 state. We attribute the

96 requirement for exogenous serine/glycine in part to the need for glutathione synthesis and

97 determined that the G0/G1 cell cycle arrest that occurs in response to serine/glycine restriction

98 occurs in an EIF2 $\alpha$-dependent manner.

99

100

101 


\section{Results}

103 Serine availability and metabolism is dysregulated in aged skeletal muscle

Analysis of human skeletal muscle biopsy tissue identified serine as the only measured

105 amino acid that was reduced in the skeletal muscle of older adults compared to younger adults

106 (Figure 1A). Further, chronological age and skeletal muscle serine levels were negatively

107 correlated (Figure 1B). This finding is supported by a previous cross-sectional analysis of

108 plasma from healthy, younger and older individuals which demonstrated that serine levels are

109 reduced in older humans (Kouchiwa et al., 2012). Others have demonstrated that in frail older

110 adults, skeletal muscle concentrations of serine and also glycine are reduced (Fazelzadeh et al.,

111 2016). Coupled with lower circulating levels, decreased skeletal muscle serine levels suggest that

112 after injury and myofiber disruption the $h \mathrm{MPC}$ microenvironment of aged individuals has less

113 serine and potentially less glycine available.

114 To determine what limits serine levels in older skeletal muscle, we measured the gene

115 expression of the serine transporter $S L C 1 A 5$ in skeletal muscle tissue homogenates from younger

116 and older adults and found no age-related differences in expression (Figure 1C). We next

117 measured gene expression of the serine synthesis enzymes, $P H G D H, P S A T 1$, and PSPH in

118 skeletal muscle tissue homogenates. PSAT1 was the only gene that was differentially expressed

119 in skeletal muscle with age (1.4-fold greater in older vs. younger, Figure 1D). Thus, it is unclear

120 whether impaired uptake or biosynthesis limits serine levels in old muscle tissue. 
bioRxiv preprint doi: https://doi.org/10.1101/833798; this version posted November 7, 2019. The copyright holder for this preprint (which was not certified by peer review) is the author/funder, who has granted bioRxiv a license to display the preprint in perpetuity. It is made available under aCC-BY-NC-ND 4.0 International license.

A

탕 Young $(n=43)$ 하 Old $(n=15)$

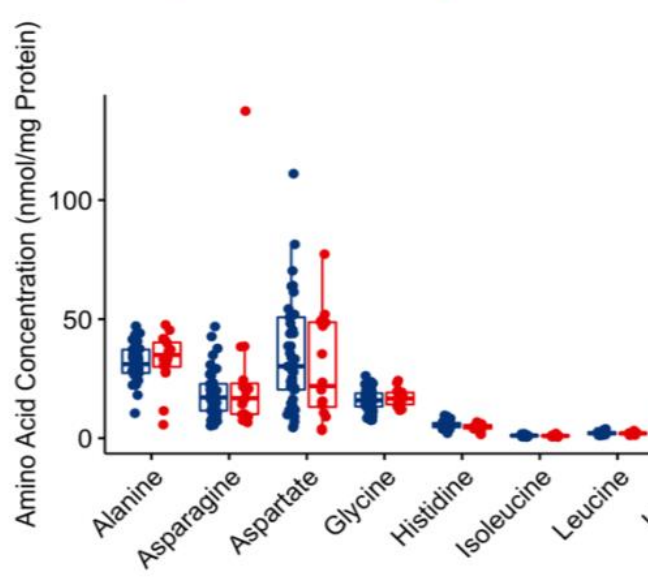

B

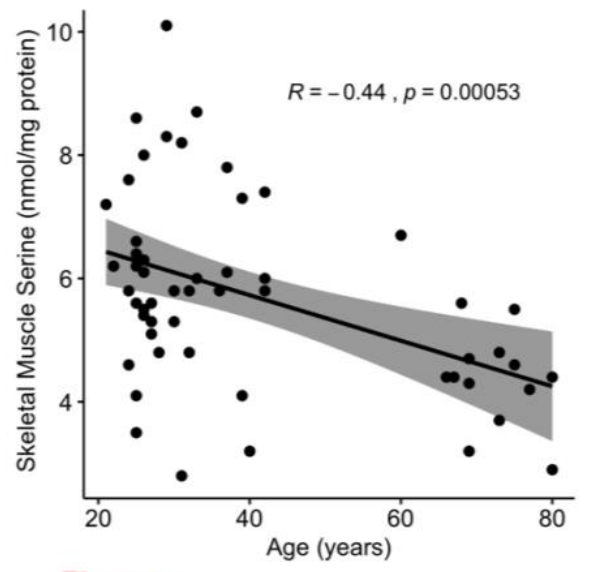

C

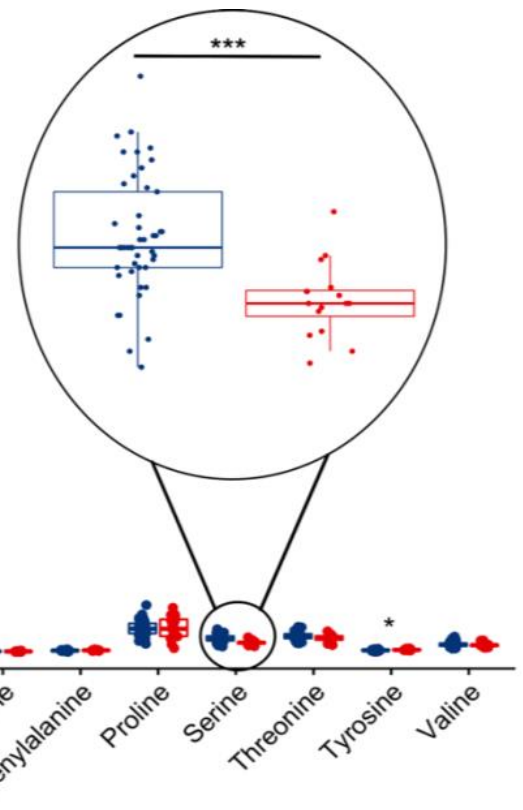

Glucose

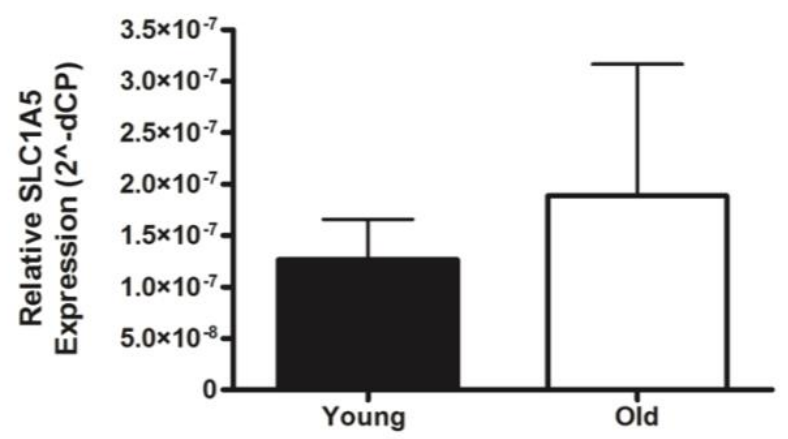

Glycolysis
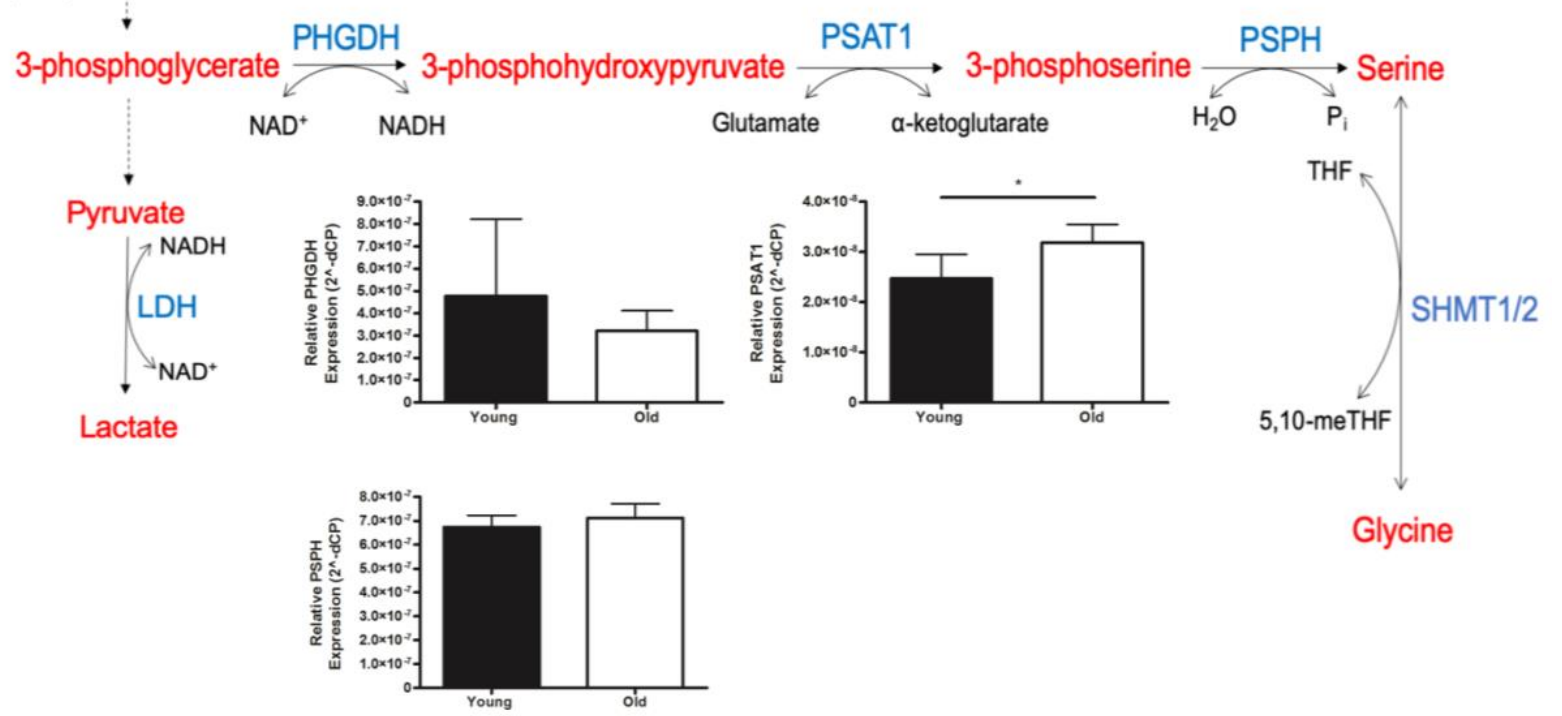

Glycine 
122 Figure 1. Serine availability and metabolism are dysregulated in aged skeletal muscle and

$123 h \mathrm{MPCs}$.

124 A) Analysis of amino acid levels in skeletal muscle biopsy tissue from younger (20-45y,

$125 \mathrm{n}=43)$ and older $(60-80 \mathrm{y}, \mathrm{n}=15)$ donors identify serine as the only amino acid that

126 decreases with age $(\mathrm{P}<0.001)$. The normalcy of the distribution of each amino acid was

127 assessed by the Shapiro-Wilk test. If data were determined to be normally distributed,

128 they were compared via an unpaired t-test otherwise they were compared Mann-Whitney

129 U-test.

130 B) Skeletal muscle serine levels are negatively correlated with age $(\mathrm{n}=58, \mathrm{r}=-.44, \mathrm{P}<0.0001)$

131 based on a Pearson correlation.

132 C) Gene expression of the serine transporter SLC1A5 (P>0.05) between skeletal muscle

133 tissue from younger $(n=11)$ and older donors $(n=10)$. Data expressed as mean \pm SD.

134 D) A schematic of the serine/glycine biosynthesis pathway. Intermediary metabolites in red.

135 Key enzymes in blue. PHGDH, phosphoglycerate dehydrogenase; PSAT1, phosphoserine

136 amino transferase 1; PSPH, phosphoserine phosphatase; SHMT 1/2, serine hydroxy

137 methyltransferase1/2; LDH, lactate dehydrogenase. Gene expression of PHGDH

$138(\mathrm{P}>0.05)$, PSAT1 $(\mathrm{P}<0.05)$, and PSPH $(\mathrm{P}>0.05)$ between skeletal muscle tissue from

139 younger $(n=11)$ and older donors $(n=10)$. Data expressed as mean \pm SD.

$140 \quad * \mathrm{P}<0.05$ 


\section{Serine and glycine are required for hMPC population expansion}

Because skeletal muscle serine levels and the regenerative potential of $h \mathrm{MPCs}$ decline with advancing age, and because serine has previously been shown to be the third most consumed metabolite by proliferating mammalian cells (Hosios et al., 2016) we evaluated whether serine and/or glycine impact $h \mathrm{MPC}$ population expansion. Serine and glycine were considered alone or in combination due to their interconversion through one enzymatic step via the serine hydroxymethyltransferase (SHMT, Figure 1D). When $h \mathrm{MPC}$ were cultured without serine and glycine, they did not undergo population expansion (Figure 2A). The addition of serine (Figure 2B) and glycine (Figure 2C) individually or in combination (Figure 2A) increased $h \mathrm{MPC}$ population expansion in a dose-dependent manner. At high doses, glycine alone was more effective at increasing $h \mathrm{MPC}$ population expansion than serine (Figure 2D). This is dissimilar to what is observed in other cell types in which serine and not glycine is required for population expansion (Labuschagne et al., 2014; Ma et al., 2017). We verified that serine/glycine restriction in the media reduced intracellular serine and glycine levels (Figure 2E).

To determine the physiological relevance of the serine and glycine concentrations used in vitro, we measured plasma serine and glycine concentrations from humans under fasting, resting conditions. The levels of plasma serine were between 76 and $212 \mu \mathrm{mol} / \mathrm{L}$ and plasma glycine were between 178 and $632 \mu \mathrm{mol} / \mathrm{L}$ (Figure 2F). However, the levels of these amino acids in circulation are frequently elevated above basal values in the non-fasted state (Gannon et al., 2002; Garofalo et al., 2011) Further, it is likely, that the localized, skeletal muscle availability is also a contributing factor. The physiological relevance of the concentrations used for cell culture experiments are also supported by an analysis by Bergström et al. demonstrating that in younger 
bioRxiv preprint doi: https://doi.org/10.1101/833798; this version posted November 7,2019. The copyright holder for this preprint (which was not certified by peer review) is the author/funder, who has granted bioRxiv a license to display the preprint in perpetuity. It is made available under aCC-BY-NC-ND 4.0 International license.

167 adults, skeletal muscle concentrations of serine and glycine are $\sim 980 \mu \mathrm{mol} / \mathrm{L}$ and $\sim 1330 \mu \mathrm{mol} / \mathrm{L}$,

168 respectively (Bergström et al., 2017).

169

A

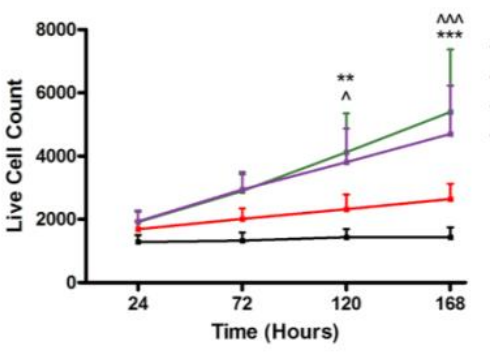

B

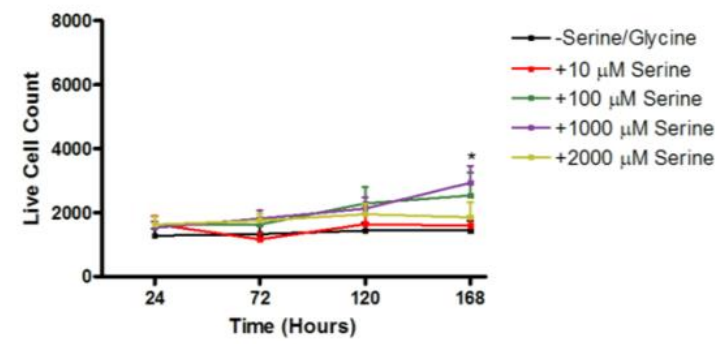

C

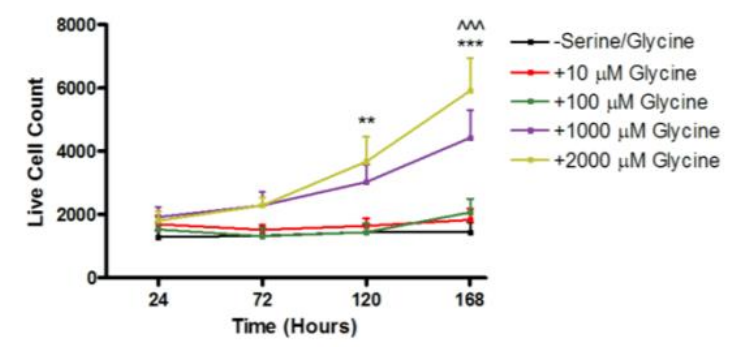

D

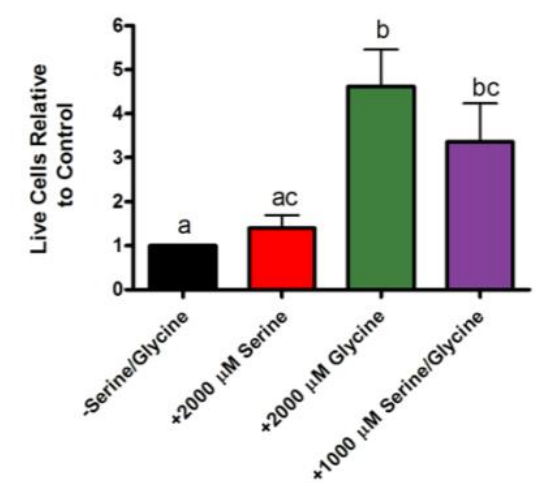

E

Treatment +Serine/Glycine 审 Serine/Glycine

F
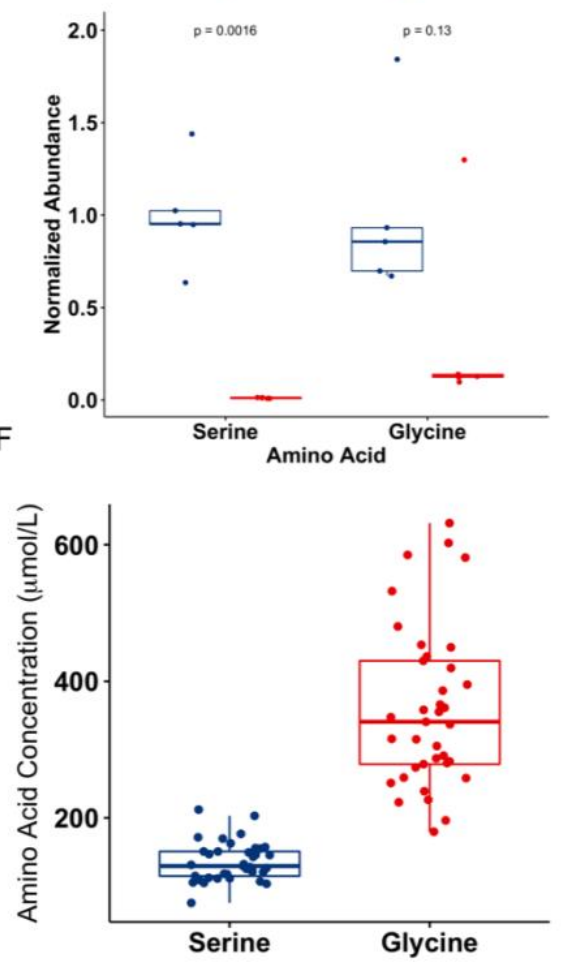
171 Figure 2. Serine and glycine are essential for $h \mathrm{MPC}$ population expansion.

172 Live cell count was determined by co-staining cells with Hoescsht 33342 (to identify all cells)

173 and propidium iodide (to identify dead cells) after $h$ MPCs were cultured in media lacking

174 serine/glycine or increasing concentrations of

175 A) serine/glycine (**indicates significant difference between $100 \mu \mathrm{M}$ vs. -serine/glycine,

$176 \mathrm{P}<0.01$, ***indicates significant difference between $100 \mu \mathrm{M}$ vs. -serine/glycine, $\mathrm{P}<0.001$,

$177 \wedge$ indicates significant difference between $1000 \mu \mathrm{M}$ vs. -serine/glycine, $\mathrm{P}<0.05, \wedge \wedge \wedge$ indicates

178 significant difference between $1000 \mu \mathrm{M}$ vs. -serine/glycine, $\mathrm{P}<0.001)$,

179 B) serine alone (*indicates significant difference between $1000 \mu \mathrm{M}$ vs. -serine/glycine, $\mathrm{P}<0.05$ ),

180 or

181 C) glycine alone (**indicates significant difference between $2000 \mu \mathrm{M}$ vs. -serine/glycine,

$182 \mathrm{P}<0.01$, ***indicates significant difference between $2000 \mu \mathrm{M}$ vs. -serine/glycine, $\mathrm{P}<0.001$,

$183 \wedge \wedge$ indicates significant difference between $1000 \mu \mathrm{M}$ vs. -serine/glycine, $\mathrm{P}<0.001)$ Data are

184 expressed as mean $\pm \mathrm{SD}$.

185 D) The relative number of live cells after seven days of culture with the indicated concentrations

186 of serine, glycine, or serine and glycine. Different letters are significantly different from each

187 other.

188 E) Levels of serine and glycine after 7 days of culture in serine/glycine restricted media as

189 determined by GC-MS.

190 F) Levels of serine and glycine in the plasma of fasted, young humans ( $n=37)$ based on GC-MS

191 measurements.

192

193 
Serine/glycine restriction causes cell cycle arrest

We next sought to understand what drives differences in $h \mathrm{MPC}$ population expansion when $h$ MPCs are cultured with and without serine/glycine. We observed that differences in

197 population expansion, during serine/glycine restriction, could not be explained by cell death

198 (Figure 3A). Using DNA staining and analysis via flow cytometry, we observed a greater

199 number of cells in the early phases of the cell cycle with serine/glycine restriction (Figure 3B).

200 This finding was supported by reduced incorporation of BrdU into DNA after a 24-hour pulse

201 (Figure 3C) and an accumulation of CYCLIN D1 protein in $h$ MPCs cultured in serine/glycine

202 restricted media (Figure 3D). Because $h$ MPC differentiation is modeled in vitro by serum

203 restriction (Pavlidou et al., 2017), we measured the $h$ MPC specific, mid-to late-differentiation

204 marker MYOGENIN, which was undetectable (Figure 3E). Additionally, levels of PAX7 and

205 MYOD were significantly elevated in serine/glycine restricted $h$ MPCs (Figure 3E). Elevated

206 MYOD levels further supports cell cycle arrest in G1; MYOD protein levels are typically

207 increased in $h$ MPCs during G1 of the cell cycle (Kitzmann et al., 1998).

208 Previously, several proliferative cell types have demonstrated an exogenous requirement

209 for serine/glycine (Labuschagne et al., 2014; Ma et al., 2017). The serine/glycine requirement in

210 these cell types was attributed to DNA synthesis as the proliferative arrest can be rescued by

211 glycine and formate, a one carbon unit integrated into the purine ring structure and necessary for

212 the synthesis of thymidine, or by exogenous nucleotides. In contrast, in $h \mathrm{MPCs}$ the

213 serine/glycine requirement appears to be derived from glycine (Figure 2CD) and is not DNA

214 synthesis based as supplementation with nucleotide precursors did not rescue $h$ MPC population

215 expansion (Figure 3F). 
bioRxiv preprint doi: https://doi.org/10.1101/833798; this version posted November 7, 2019. The copyright holder for this preprint (which was not certified by peer review) is the author/funder, who has granted bioRxiv a license to display the preprint in perpetuity. It is made available under aCC-BY-NC-ND 4.0 International license.

A

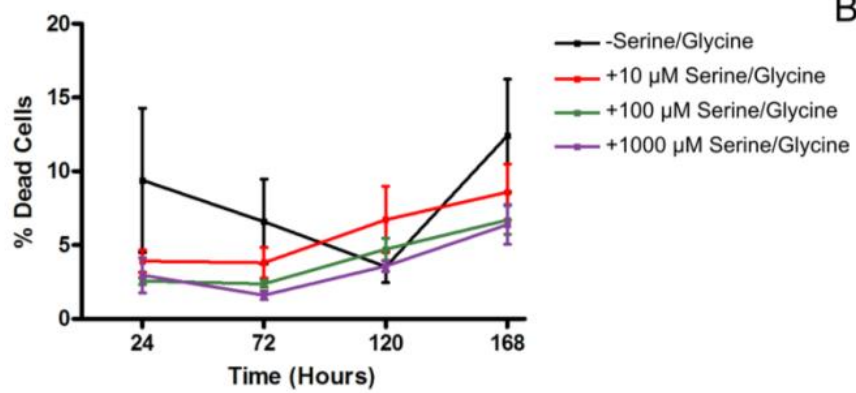

C
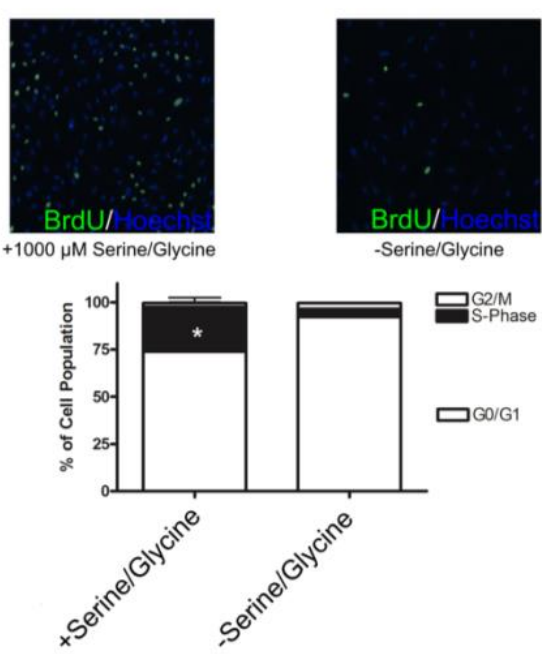

$\mathrm{E}$
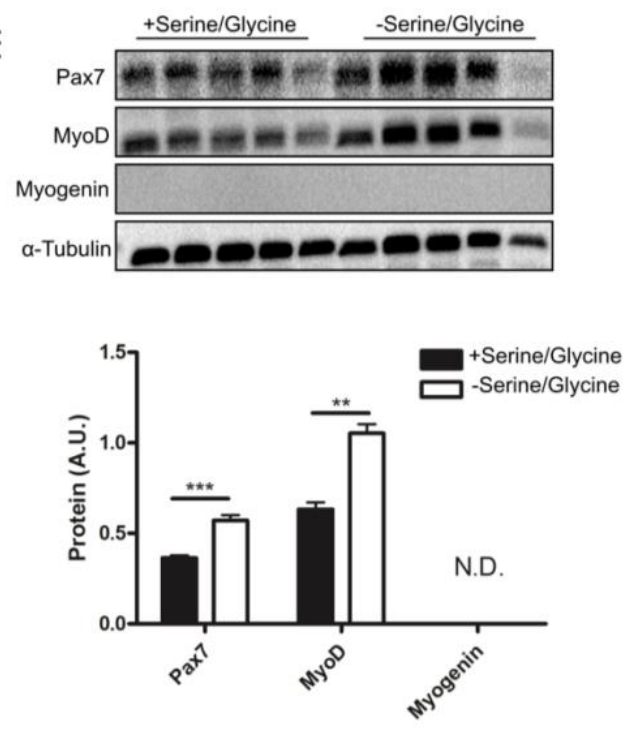

B

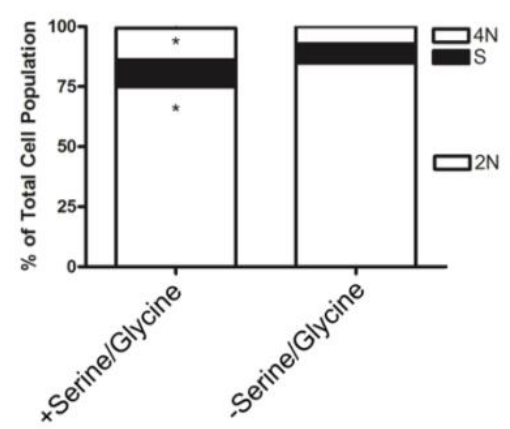

D + Serine/Glycine -Serine/Glycine
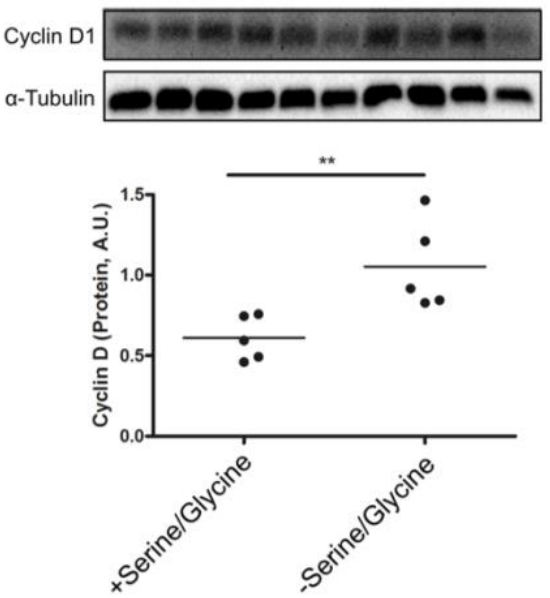

F
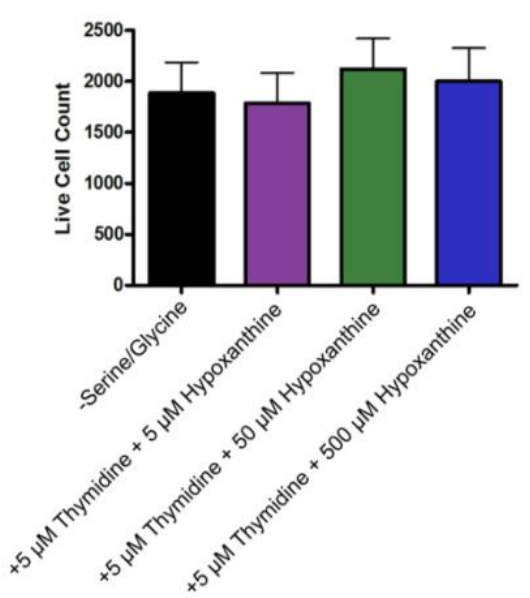
220 Figure 3. Serine/glycine restriction causes cell cycle arrest in G0/G1 in $h \mathrm{MPCs}$.

221 A) Percentage of dead cells was quantified by dividing all $h$ MPCs which stained positive for propidium iodide by all $h$ MPCs which stained positive for Hoechst 33342 after 5 days of culture in media with varying concentrations of serine/glycine.

B) Propidium iodide staining and analysis via flow cytometry was used to determine DNA content of $h$ MPCs after 5 days of serine/glycine restriction. $* \mathrm{P}<0.05$.

C) BrdU incorporation in after a 24-hour pulse in $h \mathrm{MPC}$ undergoing serine/glycine restriction for 5 days. Data are expressed as mean \pm SD.

D) Immunoblot for CYCLIN D1 protein normalized to $\alpha$-TUBULIN for quantification in $h \mathrm{MPCs}$ that had been serine/glycine restricted for 5 days. $* * \mathrm{P}<0.01$. for quantification in $h \mathrm{MPCs}$ that had been serine/glycine restricted for 5 days. $* * \mathrm{P}<0.01$,

235 All experiments were repeated with $h \mathrm{MPCs}$ derived from the same 5 donors. 
hMPCs exhibit limited capacity for serine/glycine biosynthesis

We hypothesized that $h \mathrm{MPCs}$ lack the ability for de novo serine/glycine biosynthesis, and this hypothesis, RNA-seq analyses revealed that $h \mathrm{MPCs}$ drastically upregulate serine/glycine

247 biosynthesis genes in response to serine/glycine restriction (Figure 4A, Table S1). We further

248 verified that the enzymes directly implicated in serine/glycine biosynthesis (PHGDH, PSPH,

249 PSAT1, SHMT1, SHMT2) are expressed at the protein level and the serine synthesis proteins,

250 specifically, are upregulated in response to serine/glycine restriction (Figure 4B). The serine

251 synthesis pathway branches from glycolysis at 3-phosphoglycerate, using glucose as the initial

252 substrate (Figure 1D); however, glucose uptake did not increase after serine/glycine restriction

253 (Figure 4C). Further, increasing glucose concentrations in the media did not affect $h \mathrm{MPC}$

254 proliferation in the absence of serine/glycine (Figure 4D), which suggests a limited capacity for

255 serine/glycine biosynthesis by $h$ MPCs. Using stable isotope tracing with ${ }_{13}$ C6 glucose, we

256 determined that de novo biosynthesis accounts for no detectable intracellular serine and glycine

257 when serine/glycine are available in the media (Figure 4E). During serine/glycine restriction, de

258 novo biosynthesis contributes $\sim 25 \%$ of serine and $\sim 5 \%$ of glycine to the intracellular pools

259 (Figure 4E) demonstrating that $h$ MPCs have the capacity for serine/glycine biosynthesis under

260 restricted conditions. However, the increase in de novo biosynthesis is ineffective to maintain the

261 requirements for population expansion as highlighted by the low levels of relative serine and

262 glycine even when de novo biosynthesis is active (Figure 2E). Even if $h \mathrm{MPCs}$ were able to

263 synthesize sufficient serine and glycine to support proliferation, we identified that primary

$264 h$ MPCs from older adults have reduced expression of the serine biosynthesis enzyme PHGDH,

265 (Figure 4F, n=10) suggesting that $h \mathrm{MPC}$-intrinsic de novo serine synthesis is likely impaired. 

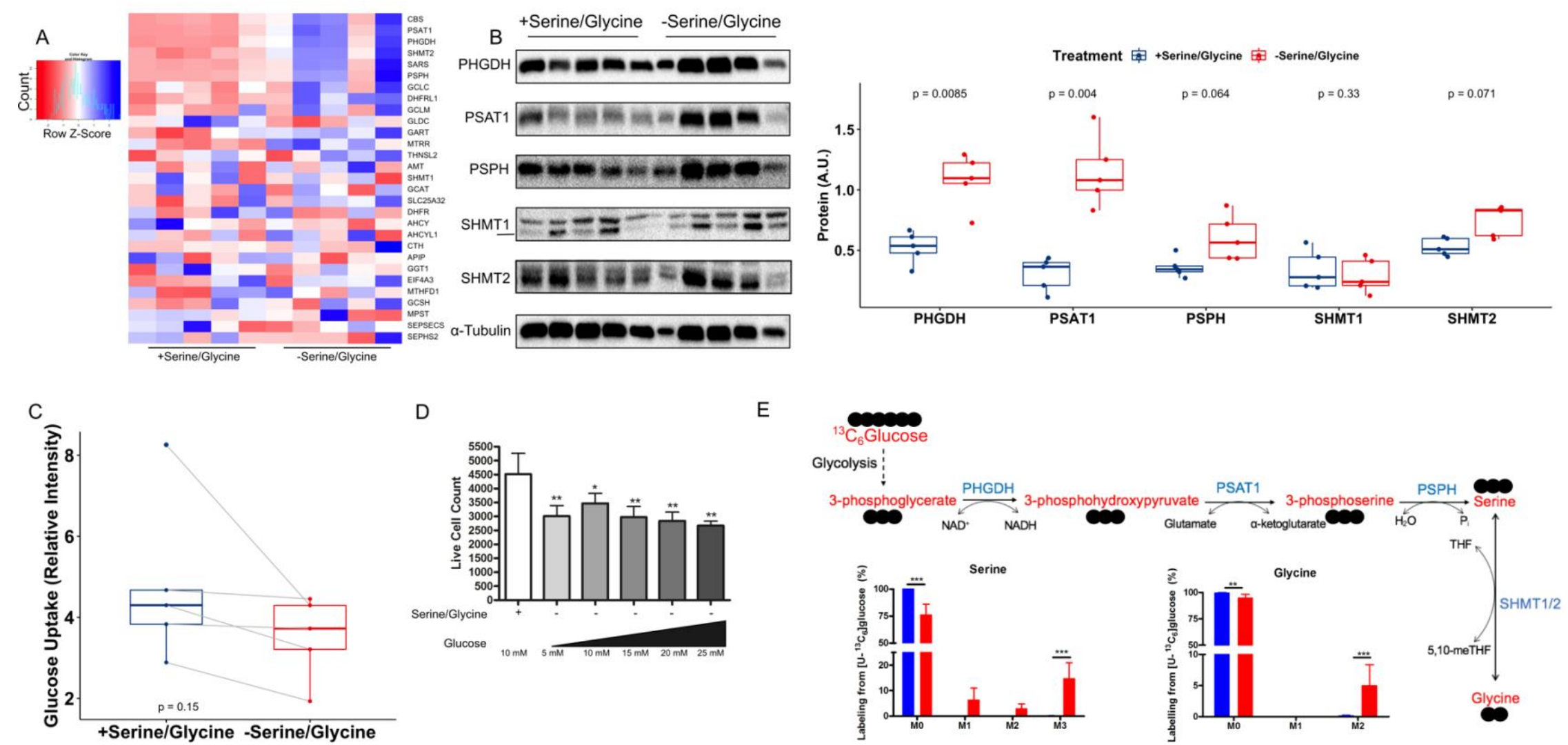

E
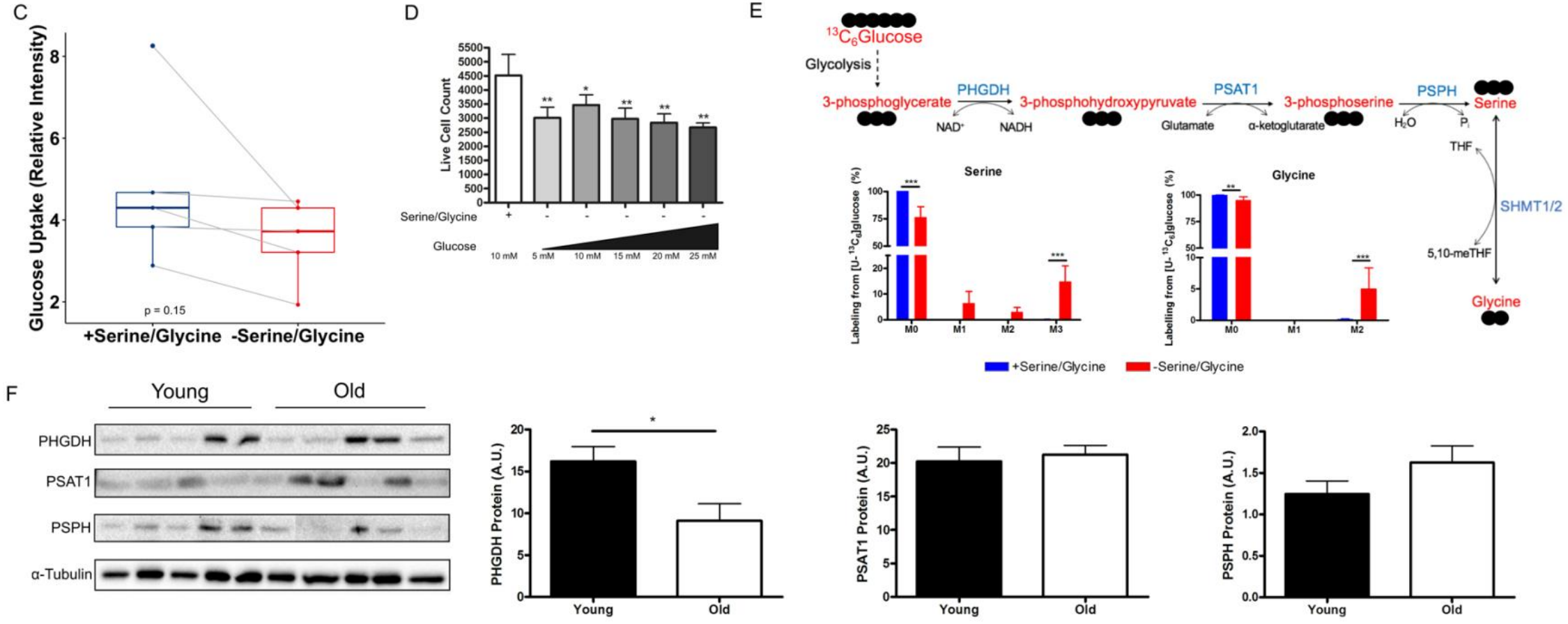
268 Figure 4. $h$ MPCs exhibit limited capacity for serine/glycine biosynthesis.

269

270

271

272

273

274

275

276

277

278

279

280

281

282

283

284

285

286

287 288

289

A) Heatmap of genes involved in serine, glycine, and one-carbon metabolism based on RNA-sequencing data from $h \mathrm{MPCs}$ after 5 days of culture in serine/glycine replete (1000 $\mu \mathrm{M})$ or restricted conditions.

B) Immunoblots for PHGDH, PSAT1, PSPH, SHMT1, and SHMT2 protein normalized to $\alpha$ TUBULIN for quantification in $h \mathrm{MPCs}$ that had been serine/glycine restricted for 5 days.

C) Glucose uptake by $h \mathrm{MPCs}$ after 5 days of culture in serine/glycine replete or restricted conditions.

D) Live cell count of $h \mathrm{MPCs}$ cultured in serine/glycine replete media or serine/glycine restricted media and varying doses of glucose. $* \mathrm{P}<0.05, * * \mathrm{P}<0.01$ relative to serine/glycine containing control. Data are expressed as mean \pm SD.

E) Percent mass isotopomer distribution of [U-13C]-glucose-derived serine and glycine in $h \mathrm{MPCs}$ cultured in serine/glycine replete $(1000 \mu \mathrm{M})$ or restricted media for 5 days followed by 48 hours in similar media but containing [U-13C]-glucose. Data are expressed as mean $\pm \mathrm{SD}$.

F) Protein levels of the serine/glycine biosynthesis enzymes PHGDH, PSAT1, and PSPH in $h$ MPCs obtained from younger $(\mathrm{n}=5)$ and older $(\mathrm{n}=5)$ individuals as determined by immunoblotting. $* \mathrm{P}<0.05$. Data expressed as mean $\pm \mathrm{SD}$.

All experiments were repeated with $h \mathrm{MPCs}$ derived from the same 5 donors. P-values are indicated on the appropriate graphs. 
Serine/glycine restriction promotes oxidative stress in hMPCs and depletes intracellular

291 glutathione

Several genes related to glutathione biosynthesis were upregulated with serine/glycine

293 depletion in the transcriptomic dataset (Figures 4A, Figure 5A, Table S1). Because glycine is

294 one of the three amino acids that comprise the tripeptide glutathione, we hypothesized that

295 serine/glycine restriction reduced glutathione levels in $h$ MPCs and impaired population

296 expansion. Serine/glycine restriction decreased total glutathione levels by approximately 9-fold

297 in $h$ MPCs (Figure 5B) and decreased the ratio of GSH:GSSG (Figure 5C). As would be

298 expected with lower glutathione levels, the primary intracellular antioxidant, we observed an

299 increase in the levels of reactive oxygen species (ROS, Figures 5D). Supplementation with a cell

300 permeable version of glutathione, glutathione ethyl ester (GSHee), modestly increased

301 intracellular glutathione levels (Figure 5E) and decreased ROS levels (Figure 5F). Despite only

302 a modest effect on intracellular glutathione levels, GSHee did provide a minor rescue to $h \mathrm{MPC}$

303 population expansion (Figure 5G). Of note, high levels of cell permeable glutathione were toxic

304 (Figure S1) and therefore, we were not able to investigate how increasing intracellular levels of

305 glutathione to that observed in serine/glycine replete cells would impact $h$ MPC population

306 expansion. We propose that ROS, associated with $h$ MPC proliferation, cannot be

307 counterbalanced during serine/glycine restriction due to reduced glutathione synthesis caused by

308 limited serine/glycine synthesis leading to cell cycle arrest. 
bioRxiv preprint doi: https://doi.org/10.1101/833798; this version posted November 7, 2019. The copyright holder for this preprint (which was not certified by peer review) is the author/funder, who has granted bioRxiv a license to display the preprint in perpetuity. It is made available under aCC-BY-NC-ND 4.0 International license.

A

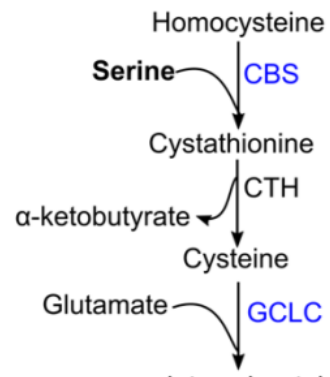

Y-glutamylcysteine

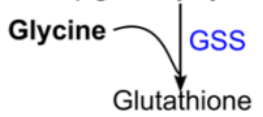

D

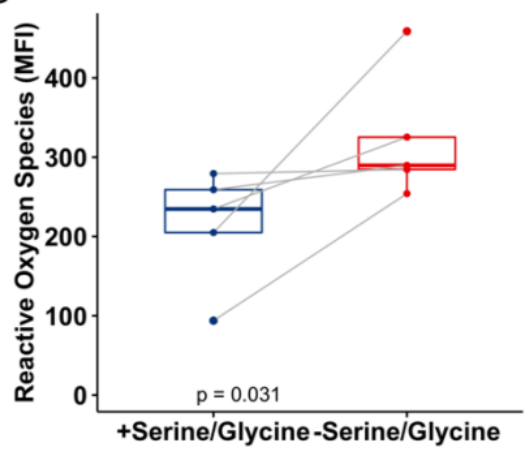

G

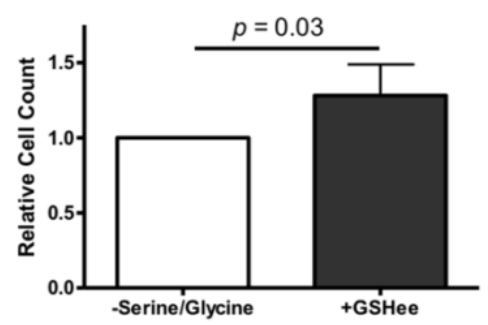

310

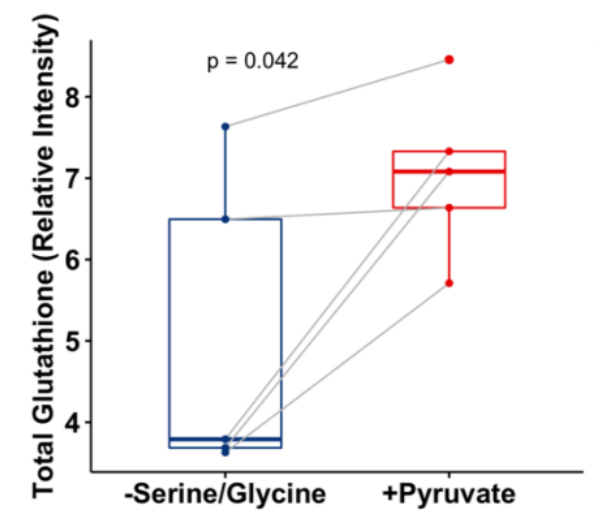

$\mathrm{B}$

E
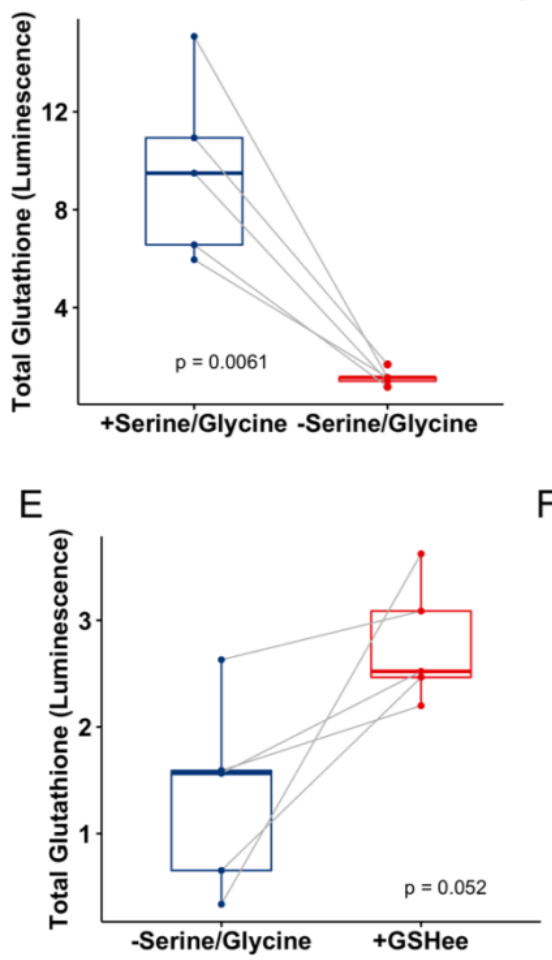

$\mathrm{H}$

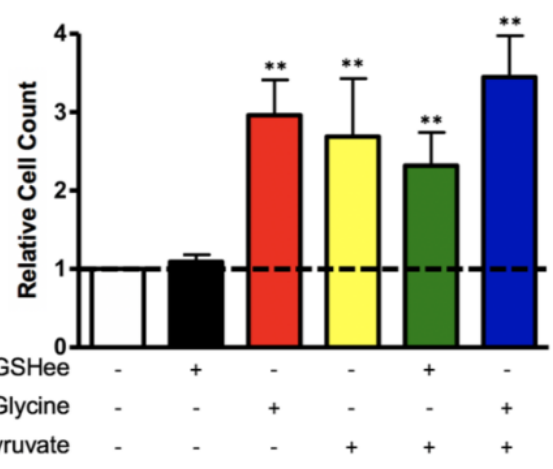

J

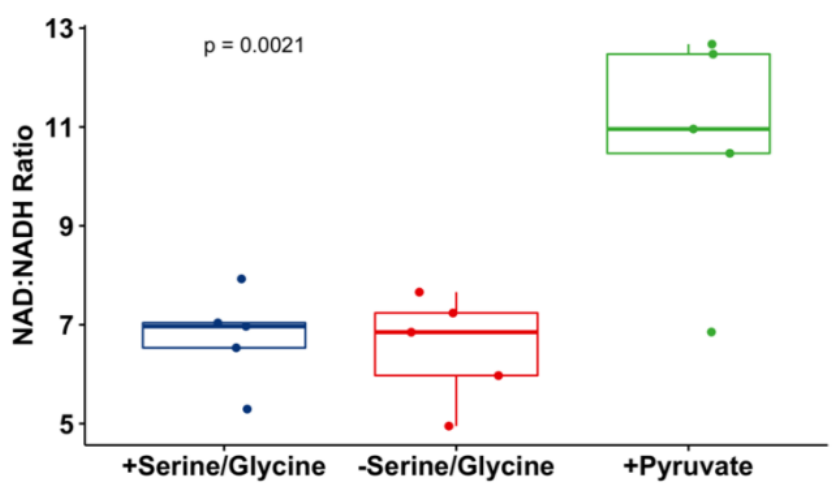


312 Figure 5. Serine/glycine restriction impairs glutathione synthesis but can be rescued by pyruvate

313 supplementation.

314 A) The glutathione synthesis pathway with genes upregulated after serine/glycine restriction

315 according to RNA-sequencing in blue. CBS, cystathionine $\beta$-synthase; CTH,

316 cystathionine gamma-lyase; GCLC, glutamate-cysteine ligase catalytic subunit; GSS,

317 glutathione synthetase.

318 B) Total intracellular glutathione levels in $h$ MPCs after 5 days in serine/glycine restricted or 319 replete media.

320 C) Ratio of reduced to oxidized intracellular glutathione levels in $h$ MPCs after 5 days in 321 serine/glycine restricted or replete media. GSH, reduced glutathione; GSSG, oxidized 322 glutathione.

323 D) Reactive oxygen species in $h$ MPCs after 5 days in serine/glycine restricted or replete 324 media.

325 E) Total intracellular glutathione levels in $h$ MPCs after 5 days of serine/glycine restriction 326 with or without $10 \mu \mathrm{M}$ cell permeable glutathione ethyl ester (GSHee).

327 F) Reactive oxygen species in $h$ MPCs after 5 days of serine/glycine restriction with or $328 \quad$ without $10 \mu \mathrm{M}$ GSHee.

329 G) Live cell count after 5 days of serine/glycine restriction with or without GSHee $(10 \mu \mathrm{M})$.

$330 \mathrm{H})$ Live cell count after 5 days of the indicated combination and concentration of

$331 \quad$ serine/glycine, GSHee, and pyruvate. $* * \mathrm{P}<0.01$

332 I) Total glutathione levels in $h$ MPCs cultured in a serine/glycine restricted media with or 333 without $1 \mathrm{mM}$ pyruvate for 5 days. 
J) Ratio of oxidized NAD (NAD+):reduced NAD (NADH) in $h \mathrm{MPCs}$ cultured in restricted serine/glycine media or media containing $1000 \mu \mathrm{M}$ serine/glycine or $1 \mathrm{mM}$ pyruvate.

336 All experiments were repeated with $h$ MPCs derived from the same 5 donors. P-values are

337 indicated on the appropriate graphs.

338 
Pyruvate rescues hMPC proliferation during serine/glycine restriction

Under the assumption that inadequate glycine availability prevents adequate glutathione

359 synthesis and ROS scavenging, we provided pyruvate in the absence of serine/glycine as an

360 alternative antioxidant; we observed a complete rescue of the proliferative defect caused by

361 serine/glycine restriction (Figure 5H). Pyruvate also increased total glutathione levels (Figure

362 5I). An additional mechanism by which pyruvate supplementation may have rescued $h \mathrm{MPC}$

363 proliferation, during serine/glycine restriction, is by increasing the NAD+/NADH ratio through

364 the reduction of pyruvate to lactate, which provides the necessary NAD+ cofactor for serine

365 biosynthesis (i.e., for the conversion of 3-phosphoglycerate to 3-phosphohydroxypyruvate,

366 Figure 1C). Supporting this mechanism, pyruvate supplementation, in the absence of exogenous

367 serine/glycine, increased the NAD+/NADH ratio which has recently been identified as the

368 limiting cofactor for serine biosynthesis (Diehl et al., 2019) (Figure 5J).

369 Serine/glycine restriction induces the integrated stress response in hMPCs

370 We hypothesized that ATF4 may integrate the sensing of serine/glycine restriction and

371 underlie the transcriptional upregulation of the serine/glycine biosynthetic genes (Figure 4A).

372 We noted several ATF4 target genes that were affected by serine/glycine restriction in $h$ MPCs

373 (Figure 6A). We further verified that protein levels of ATF4 and its upstream regulator, p-eIF2 $\alpha$,

374 are increased after serine/glycine restriction (Figure 6B). Phosphorylation of eIF2 $\alpha$ is known to

375 coordinate a global decline in protein synthesis. In support of this, in the absence of

376 serine/glycine, we observed an accumulation of most of the free, non-serine/glycine amino acids

377 (Figure 6C) and a trend towards reduced protein synthesis (assessed by puromycin

378 incorporation, Figure 6D). 
380 proliferation, $h$ MPCs were cultured with the small molecule, p-eIF2 $\alpha$ inhibitor, ISRIB (Sidrauski

381 et al., 2015) (Figure 6E). Treatment with ISRIB increased $h$ MPC cell number in the absence of

382 serine/glycine (Figure 6F). Interestingly, ISRIB treatment, in the presence of serine/glycine,

383 negatively affected cell number (Figure S2) suggesting that the benefit of reducing p-eIF2 $\alpha$

384 signaling on $h \mathrm{MPC}$ proliferation was only effective when aberrant signaling was induced by

385 serine/glycine restriction. Therefore, we propose that serine/glycine restriction reduces the

386 intracellular availability of serine, glycine, and glutathione, which activates the integrated stress

387 response and leads to limited global translation and further to cell cycle arrest (Figure 6G).

388 Overall, this process is likely exacerbated in older adults who lose serine availability in the

389 microenvironment. 


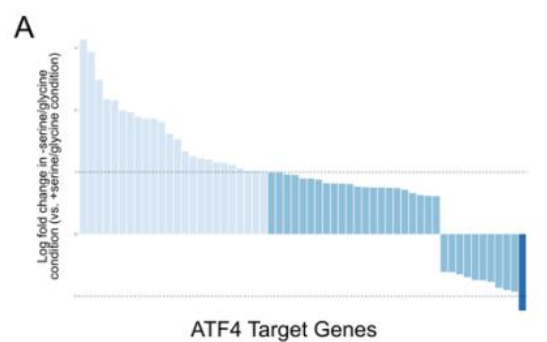

C
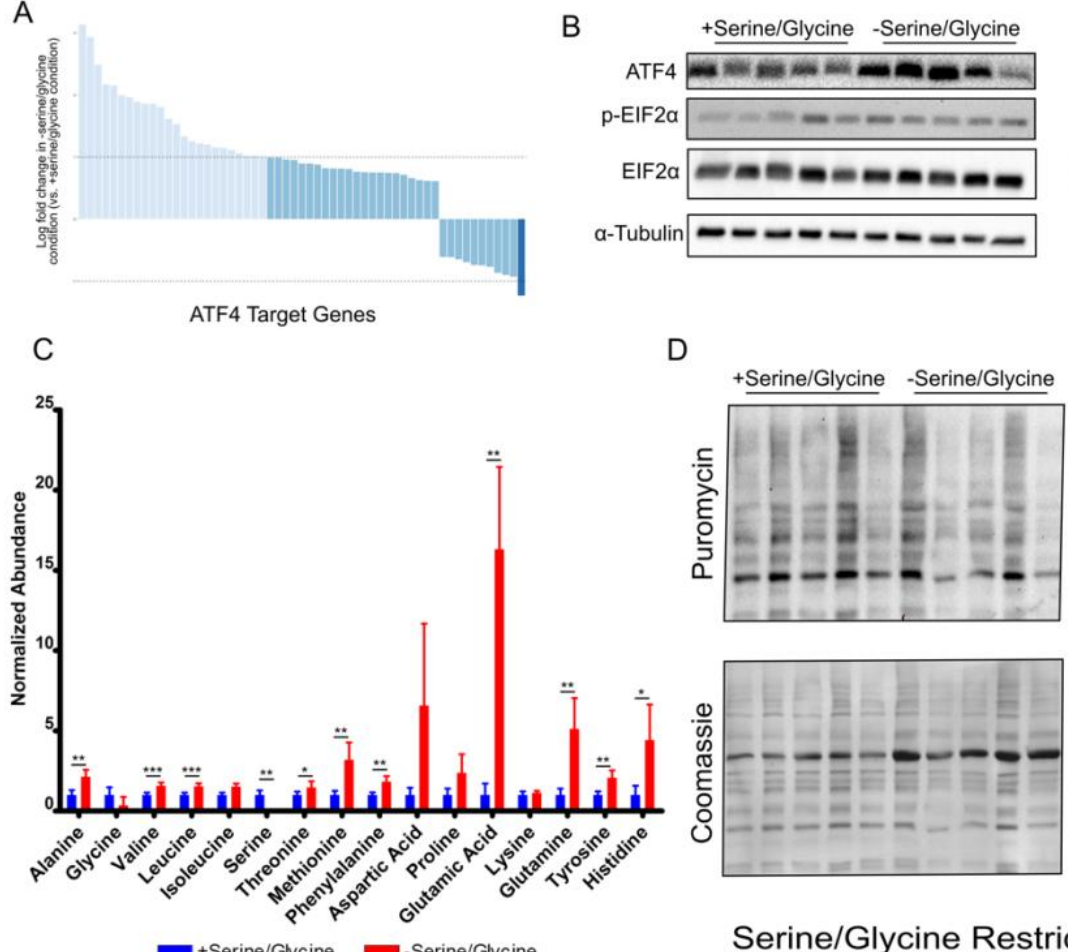

Serine/Glycine Restriction

$\mathrm{E}$

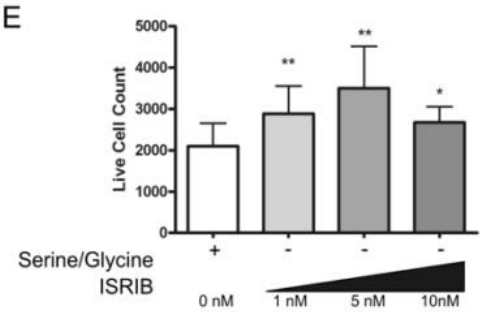

F

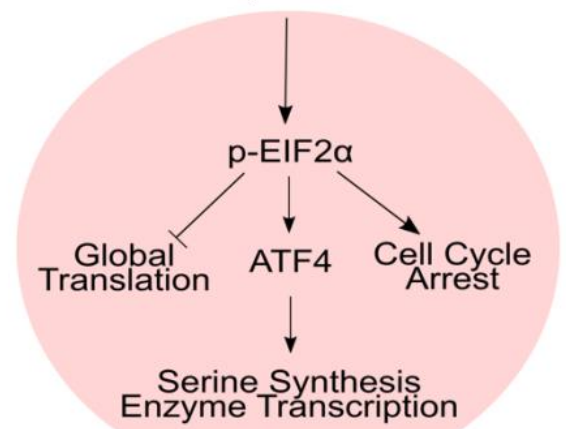

Figure 6. Serine/glycine restriction activates ATF4 in a p-EIF $\alpha$ dependent manner causing

$394 \quad h$ MPC proliferation arrest.

A) Expression of known ATF4 targets based on RNA-sequencing of $h \mathrm{MPCs}$ cultured in serine/glycine restricted media or serine/glycine replete media for 5 days. Average log fold change of transcripts in serine/glycine restricted samples vs. serine/glycine replete samples. Dark blue indicates fold change $<-1$ and light blue indicates fold change $>1$. 
B) Left, protein levels of ATF4, p-eIF2 $\alpha$, and total eIF2 $\alpha$ determined by immunoblotting $h \mathrm{MPCs}$ cultured in serine/glycine replete or restricted media. All proteins were normalized to $\alpha$-TUBULIN expression. Right, quantification of protein expression.

C) Intracellular amino acid abundance, normalized to total ion count, in $h \mathrm{MPC}$ cultured in serine/glycine replete or restricted media for 5 days.

D) Left, immunoblot analysis for puromycin incorporation of $h$ MPCs cultured in serine/glycine replete or restricted media for 5 days normalized to Coomassie staining. Right, quantification of puromycin incorporation.

E) Protein levels of p-eIF2 $\alpha$ and total eIF2 $\alpha$ determined by immunoblotting in $h \mathrm{MPCs}$

F) Live cell count after 5 days of serine/glycine restriction with or without varying doses of ISRIB. global protein synthesis and cause cell cycle arrest.

414 All experiments were repeated with $h \mathrm{MPC}$ derived from the same 5 donors. P-values are 415 indicated on the appropriate graphs. 


\section{Discussion}

Here, we report that aging reduces levels of serine in the $h \mathrm{MPC}$ microenvironment and

424 that $h$ MPCs are limited in their capacity for serine/glycine biosynthesis. The negative correlation

425 between skeletal muscle levels of serine and age are in line with previous analyses comparing

426 serum of younger and older individuals (Dunn et al., 2014; Menni et al., 2013). While glycine

427 has not consistently been noted as reduced in the circulation of older adults, it has been shown to

428 be reduced in the red blood cells of older adults and these reduced levels can be corrected by

429 dietary supplementation (Sekhar et al., 2011). In support of a dysregulation of serine synthesis

430 with age, we identified changes in expression of the serine synthesis enzymes with age in whole

431 skeletal muscle tissue and in isolated $h$ MPCs. Others have previously identified that the

432 expression of metabolic enzymes and nutrient transporters can decline with age, however, the

433 underlying reason for this remains elusive (Kawase et al., 2015). While our data are supportive

434 of a decrease of serine levels in human skeletal muscle with age, potentially due to reduced

435 biosynthesis, a direct measurement is necessary to definitively answer this question. Therefore, it

436 is likely that reduced availability of serine/glycine to $h$ MPCs is due to a combination of reduced

437 de novo synthesis and dietary changes or metabolism with age.

438 The importance of decreased serine/glycine availability to $h$ MPCs with age is highlighted

439 by our identification of an absolute requirement for the non-essential amino acids, serine and

440 glycine, for $h \mathrm{MPC}$ proliferation. A previous report, in rat MPCs, demonstrated that serine and

441 glycine are required for proliferation likely due to a limited capacity for de novo serine synthesis

442 (Dufresne et al., 1976). A more recent report found that C2C12 cells, an immortalized murine

443 cell line mimicking MPCs, could proliferate in the presence of serine and absence of glycine but

444 that proliferation was enhanced with the addition of glycine (Sun et al., 2016). It is possible that 
445 glycine in the $\mathrm{C} 2 \mathrm{C} 12$ cell model is synthesized from serine to maintain necessary glycine for

446 cellular processes, however, isotope tracing was not conducted to test this theory. The work

447 presented here builds upon these previous findings by extending them into a primary, human

448 model and elucidating the mechanism for the $h \mathrm{MPC}$ serine/glycine requirement.

The skeletal muscle of older individuals has a diminished ability to regenerate after injury

450 due to a decline in the function of MPCs. It has been demonstrated that repeated muscle injury in

451 aged mice depletes the number of self-renewing MPCs and consequently skeletal muscle

452 regeneration (Sousa-Victor et al., 2014). $h$ MPCs isolated from older (vs. younger) donors exhibit

453 diminished antioxidant capacity (Fulle et al., 2005) and $h$ MPCs that are undergoing replicative

454 senescence in culture, to model aging, exhibit increased ROS levels (Minet and Gaster, 2012).

455 Together, this suggests that $h$ MPCs from older individuals may have diminished skeletal muscle

456 regeneration because of an inability to buffer the ROS produced as a natural consequence of

457 proliferation (L'Honoré et al., 2018). Serine/glycine are required for glutathione synthesis to

458 maintain physiological levels of ROS (L'Honoré et al., 2018) during proliferation as

459 demonstrated by our experiments in which supplementation of cell-permeable glutathione,

460 increased cell number in a modest but repeatable manner. Therefore, a decline in serine

461 availability in the $h \mathrm{MPC}$ microenvironment, coupled with a decline in the $h \mathrm{MPC}$-intrinsic

462 capacity for de novo serine synthesis, may prevent adequate glutathione synthesis to buffer

463 proliferation associated increases in intracellular ROS and lead to a reduction in the MPC pool in

464 older individuals. Evidence exists that dietary intervention may be able to help maintain

465 glutathione levels with advancing age. For example, a persistent metabolic phenotype associated

466 with aging skeletal muscle is increased ROS due to impaired glutathione synthesis and this

467 phenotype can be corrected with dietary supplementation of the glutathione precursors glycine 
and cysteine (Sekhar et al., 2011). Future studies should examine the effect of dietary supplementation on glutathione production by aged MPCs.

There is a growing body of literature demonstrating that dietary glycine supplementation

471 protects muscle mass and function during a number of disease states including cancer cachexia

472 (Ham et al., 2014), muscle dystrophy (Ham et al., 2019), sepsis (Ham et al., 2016), and reduced

473 calorie intake (Caldow et al., 2016). To date the beneficial effects of glycine supplementation on

474 skeletal muscle in the disease state has been attributed to glycine's systemic anti-inflammatory

475 effects, its contribution to balancing ROS signaling in whole skeletal muscle tissue, and its

476 ability to restore skeletal muscle's anabolic response to leucine (Koopman et al., 2017).

477 However, muscle dystrophy, specifically, is characterized by chronic MPC proliferation

478 (Carnwath and Shotton, 1987) and genetic perturbations in MPCs have been shown to improve

479 mouse models of muscle dystrophy by supporting maintenance of the MPC population (Gallot et

480 al., 2018). Therefore, while much research has focused on understanding the role of dietary

481 glycine supplementation on mature skeletal muscle as a mechanism for attenuating disease

482 related skeletal muscle loss our data suggest that such dietary supplementation may also

483 contribute to skeletal muscle maintenance by supporting MPC proliferation.

We demonstrate that inadequate intracellular serine/glycine and/or subsequent alterations

485 in intracellular metabolism can be sensed in a p-eIF2 $\alpha$ dependent manner resulting in halted

486 protein translation and cell cycle arrest. eIF2 $\alpha$ is a stress-sensing kinase that can integrate inputs

487 from a number of signals to elicit the integrated stress response that directs ATF4 to upregulate

488 genes associated with metabolism and nutrient uptake while limiting the expression of genes that

489 are non-essential for immediate survival (Harding et al., 2003). The serine/glycine biosynthesis

490 enzymes have been identified as ATF4 targets (DeNicola et al., 2015), highlighting the 
importance of this pathway in mediating cell survival under stress conditions. It is unknown

492 whether the stress signal, which elicited the ATF4 response in $h$ MPCs, was the low levels of

493 serine/glycine themselves, the buildup of ROS caused by reduced glutathione levels, or through

494 another mechanism. eIF2 $\alpha$ is also a primary regulator of protein translation (Holcik and

495 Sonenberg, 2005) and we demonstrated, in $h$ MPCs, that serine/glycine restriction results in a

496 reduction of protein translation and an accumulation of free amino acids. Inhibition of protein

497 translation via a number of different approaches arrests cells in the G1 phase of the cell cycle

498 (Polymenis and Aramayo, 2015). Similarly, phosphorylation of eIF2 $\alpha$ has been previously

499 shown to be associated with fibroblast arrest in the G1 phase of the cell cycle; however, in

500 opposition to our results, arrest in G1 by fibroblasts was associated with a decrease in cyclin D1

501 translation (Hamanaka et al., 2005). In quiescent MPCs eIF2 $\alpha$ is maintained in a phosphorylated

502 state and ATF4 levels are abundant (Zismanov et al., 2016). When MPCs transition from

503 activation to proliferation p-eIF2 $\alpha$ as well as ATF4 levels decline (Zismanov et al., 2016).

504 Furthermore, a point mutation in MPCs that prevents the phosphorylation of eIF2 $\alpha$ forces MPCs

505 to break quiescence, a state of cell cycle arrest, and initiate proliferation (Zismanov et al., 2016).

506 These results are similar to those found in this report when the cell cycle arrest initiated by

507 serine/glycine restriction was overcome by treatment with ISRIB, an inhibitor of p-eIF2 $\alpha$.

508 For the first time, we identified that $h \mathrm{MPCs}$ possess the capacity for de novo

509 serine/glycine biosynthesis. Intriguingly, we note that serine/glycine biosynthesis only occurs

510 when $h$ MPCs are challenged with exogenous serine/glycine restriction. Furthermore, when

511 serine/glycine synthesis does occur it is ineffective at restoring intracellular levels of

512 serine/glycine to a degree necessary to support proliferation. The limited ability of $h$ MPCs to

513 produce adequate serine/glycine is at least partially attributable to a lack of NAD+ to facilitate the 
514 conversion of 3-phosphoglycerate to 3-phosphohydroxypyruvate and eventually serine rather

515 than a lack of glucose to form 3-phosphoglycerate. This assertion is supported by the fact that

516 addition of pyruvate which is converted to lactate via lactate dehydrogenase, a reaction which

517 also oxidizes $\mathrm{NADH}$ to $\mathrm{NAD}_{+}$, increased the ratio of $\mathrm{NAD}_{+} / \mathrm{NADH}$ and rescued $h \mathrm{MPC}$

518 proliferation. Additionally, serine/glycine restriction did not increase glucose uptake nor did

519 increasing levels of available glucose influence $h$ MPC proliferation, suggesting that the

520 limitation of serine synthesis was not driven by glycolytic substrate availability. We did note that

521 serine/glycine restriction did not increase cell death and therefore it may be that serine/glycine

522 biosynthesis is upregulated in serine/glycine deplete conditions to support cell survival.

523 In conclusion, we have outlined a novel requirement for exogenous serine/glycine to

524 support $h \mathrm{MPC}$ proliferation. Furthermore, we have identified that the reduced availability of

525 extracellular and intracellular serine/glycine in aging may contribute to the decline in $h \mathrm{MPC}$ -

526 based skeletal muscle regeneration that occurs with aging. 


\section{Methods}

538

539

540

541

542

543

544

545

546

\section{7}

548

549

550

551

552

553

554

555

556

557

558

559

\section{Participants}

Younger (21-40 years) and older adults (65-80 years) were recruited from the Tompkins County, New York area. Participants were excluded if they had a history of negative or allergic reactions to local anesthetic, used immunosuppressive medications, were prescribed to anticoagulation therapy, were pregnant, had a musculoskeletal disorder, suffered from alcoholism (>11 drinks per week for women and >14 drinks per week for men) or other drug addictions, or were acutely ill at the time of participation (Gheller et al., 2019a; Riddle et al., 2018a). The Cornell University, Institutional Review Board approved the protocol and all subjects gave written informed consent in accordance with the Declaration of Helsinki.

\section{Human skeletal muscle biopsies}

Skeletal muscle tissue was obtained from the vastus lateralis muscle of humans using the percutaneous biopsy technique. Visible connective or adipose tissues were removed at the time of biopsy. For tissue homogenate experiments the biopsy sample was measured for wet weight and then snap-frozen in liquid nitrogen and stored at -80 。C. For cell culture experiments a $60-$ $100 \mathrm{mg}$ portion of the tissue was stored in Hibernate ${ }^{\circledR}-\mathrm{A}$ medium (Invitrogen) at $4 \mathrm{oC}$ until tissue disassociation was performed (within 48 hours).

\section{Amino acid analysis of human skeletal muscle tissue}

Frozen tissue samples (20-30 mg) were homogenized for 2 min using ceramic beads (Precellys 2 mL Hard Tissue Homogenizing Ceramic Beads Kit, Bertin Instruments, US) in 500 $\mu \mathrm{L}-20^{\circ} \mathrm{C}$ methanol, $400 \mu \mathrm{L}$ ice-cold saline, and $100 \mu \mathrm{L}$ ice-cold $\mathrm{H}_{2} \mathrm{O}$ containing amino acid isotope labelled internal standards (Cambridge Isotope Laboratories, \#MSK-A2-1.2). An aliquot of tissue homogenate $(50 \mu \mathrm{L})$ was dried under air and resuspended in RIPA buffer for protein 
560 quantification using bicinchoninic acid assay (BCA, BCA Protein Assay, Lambda, Biotech Inc.,

561 US). $1 \mathrm{~mL}$ of chloroform was added to the remaining homogenate and the samples were

562 vortexed for $5 \mathrm{~min}$ followed by centrifugation at $4{ }^{\circ} \mathrm{C}$ for $5 \mathrm{~min}$ at $15000 \mathrm{~g}$. The organic phase

563 was collected and the remaining polar phase was re-extracted with $1 \mathrm{~mL}$ of chloroform. An

564 aliquot of the polar phase was collected, vacuum-dried at $4{ }^{\circ} \mathrm{C}$, and subsequently derivatized with

$5652 \%(\mathrm{w} / \mathrm{v})$ methoxyamine hydrochloride (Thermo Scientific) in pyridine for 60 min following by

56630 min sialyation N-tertbutyldimethylsilyl-N-methyltrifluoroacetamide (MTBSTFA) with $1 \%$

567 tert-butyldimethylchlorosilane (tBDMS) (Regis Technologies) at $37^{\circ} \mathrm{C}$. Polar derivatives were

568 analyzed by gas chromatography (GC)-mass spectrometry (MS) using a DB-35MS column (30m

$569 \times 0.25 \mathrm{~mm}$ i.d. x $0.25 \mu \mathrm{m}$, Agilent J\&W Scientific) installed in an Agilent 7890A GC interfaced

570 with an Agilent 5975C MS as previously described (Wallace et al., 2018).

571 Amino acid analysis of human plasma

$572 \quad 3 \mu \mathrm{L}$ of human plasma were spiked with $3 \mu \mathrm{L}$ amino acid isotope labelled internal

573 standards (Cambridge Isotope Laboratories, \#MSK-A2-1.2) and extracted with $250 \mu \mathrm{L}-20{ }^{\circ} \mathrm{C}$

574 methanol for $10 \mathrm{~min}$ and centrifuged at $4^{\circ} \mathrm{C}$ for $10 \mathrm{~min}$ at $15000 \mathrm{~g} .200 \mu \mathrm{L}$ of supernatant was

575 collected, vacuum-dried at $4^{\circ} \mathrm{C}$, and derivatized with MTBSTFA and tBDMS as described for

576 muscle polar analysis.

577 Primary hMPC culture

578 Primary $h \mathrm{MPC}$ cultures were obtained as previously described (Riddle, Bender and A. E.

579 Thalacker-Mercer, 2018; Riddle, Bender and A. Thalacker-Mercer, 2018; Gheller, J. Blum, et

$580 a l ., 2019)$. Briefly, skeletal muscle tissue, stored in Hibernate ${ }^{-}$-A medium (Gibco), was minced

581 and washed via gravity with Dulbecco's PBS (Gibco) and then digested using mechanical and

582 enzymatic digestion in low glucose Dulbecco’s Modified Eagle Medium (Gibco). This solution 
was passed through a $70 \mu \mathrm{m}$ cell strainer into $5 \mathrm{~mL}$ of a growth media comprised of Ham's F12

584 (Gibco), 20\% FBS, 1\% penicillin/streptomycin (Corning), and $5 \mathrm{ng} / \mathrm{mL}$ recombinant human

585 basic fibroblast growth factor (bFGF, Promega) then centrifuged. The pelleted cells were resuspended in growth media containing $10 \%$ DMSO and cryopreserved at $-80 \mathrm{oC}$ until isolation

587 via flow cytometry. Primary $h \mathrm{MPCs}$ were sorted using fluorescence activated cell sorting with

588 fluorescently-conjugated antibodies to cell surface antigens specific to $h$ MPCs [CD56 (NCAM,

589 BD Pharmingen) and CD29 ( $\beta 1$-integrin, BioLegend)] and a viability stain (7-

590 Aminoactinomycin D, eBioscience) (Xu et al., 2015). Passage six $h$ MPCs were used for all

591 experiments and were cultured in a $5 \% \mathrm{CO}_{2}$ atmosphere at $37^{\circ} \mathrm{C}$ on collagen coated plates (Type

592 I, Rat Tail, Corning). For cell culture experiments, donor cells from females were used

593 exclusively due to availability of adequate sample.

$h \mathrm{MPCs}$ were initially seeded in the growth medium described above before being

595 switched to treatment medium 24 hours later. For all experiments a specially formulated DMEM

596 devoid of serine, glycine, methionine, choline, pyridoxine, glucose, folate, nucleotides, and

597 nucleosides that was supplemented with dialyzed and charcoal treated FBS (10\%), $200 \mu \mathrm{M}$

598 methionine, $4 \mathrm{mg} / \mathrm{L}$ pyridoxine, $5 \mathrm{ng} / \mathrm{mL}$ bFGF, $25 \mathrm{nM}$ (6S) 5-formylTHF, penicillin-

599 streptomycin (1\%), $10 \mathrm{mmol} / \mathrm{L}$ glucose, $4 \mathrm{mM}$ Glutamax (Gibco), as well as L-serine and

600 glycine in varying concentrations. Unless otherwise noted, all assays were performed after 5

601 days in the treatment medium specified as this was the time point when differences in cell

602 number between cells grown in serine/glycine restricted and replete media were initially

603 identified. In all experiments cell culture media was replenished daily. All experiments contained

604 appropriate vehicle controls (DMSO or sterile $\mathrm{H}_{2} \mathrm{O}$ ). 
For quantitative RT-PCR analysis and RNA-sequencing (RNA-seq), RNA was isolated from $h$ MPCs and using Omega E.Z.N.A.® Total RNA Kit I (Omega) according to the manufacturer's instructions. RNA was isolated from skeletal muscle biopsy tissue using Trizol

609 Reagent (Ambion) as per manufacturer's instructions. RNA quantity was determined

610 spectrophotometrically.

\section{Quantitative RT-PCR}

613 reverse transcription of extracted RNA using the Applied Biosystems High-Capacity cDNA

614 Reverse Transcription Kit. The Taqman Gene Expression System (Applied Biosystems) was

615 used to measure mRNA expression levels of phosphoglycerate dehydrogenase (PHGDH,

616 HS00358823), phosphoserine aminotransferase 1 (PSAT1, Hs00268565), and phosphoserine

617 phosphatase (PSPH, Hs01921296). All samples were normalized to $18 S$ (Hs99999901)

618 expression.

RNA library preparation and sequencing

Prior to RNA-seq, RNA quality was determined using an AATI Fragment Analyzer; all

621 samples had an RNA quality number $>8.5$. The NEBNext Ultra II RNA Library Prep Kit (New

622 England Biolabs) was used to generate TruSeq-barcoded RNA-Seq libraries. Libraries were

623 quantified with the Qubit 2.0 (dsDNA HS kit; Thermo Fisher) and size distribution was

624 measured with a Fragment Analyzer (Advanced Analytical) before pooling. A NextSeq500

625 (Illumina) was used for sequencing, and a minimum of $20 \mathrm{M}$ single-end $75 \mathrm{bp}$ reads per library

626 were obtained. Cutadapt v1.8 was used to trim low quality reads and adaptor sequences

627 (parameters: -m 50 -q 20 -a AGATCGGAAGAGCACACGTCTGAACTCCAG-match-read-

628 wild cards) (Martin, 2011). Tophat v2.1 was used to map reads to the reference genome 
629 (parameters:-library-type=fr-firststrandon-no-novel-juncs-G<ref_genes.gtf>) (Kim et al., 2013).

630 Differential gene expression analysis was performed using edgeR (McCarthy et al., 2012). Only

631 genes with at least 2 counts per million in at least three of the samples were retained for analysis.

632 Immunoblot analysis

633 For immunoblot analysis, protein was isolated from $h$ MPCs with RIPA buffer containing

634 phosphatase (PhosSTOP, Roche) and protease (cOmplete, Roche) inhibitors. The protein

635 concentration was quantified by BCA. 8-15 $\mu \mathrm{g}$ of protein was loaded on $10 \%$ SDS gels and

636 transferred to PVDF membranes. Membranes were incubated in primary antibodies PHGDH

637 (Proteintech), PSAT1 (Proteintech), PSPH (Proteintech), SHMT1 (Stover laboratory) (Woeller et

638 al., 2007), SHMT2 (Stover laboratory) (Anderson and Stover, 2009), Cyclin D1 (Cell Signaling),

639 ATF4 (Cell Signaling), phosphorylated (Ser51) p-EIF2 $\alpha$ (Cell Signaling), and total EIF2 $\alpha$ (Cell

640 Signaling) diluted (1:1000) in a chemiluminescent blocking buffer (blØkTM - CH, Millipore)

641 overnight at $4 \mathrm{oC}$. After the overnight incubation, membranes were washed with $0.1 \%$ Tween in

642 tris-buffered saline before incubation with appropriate secondary antibody (rabbit, Proteintech;

643 goat, Thermo Scientific; mouse, Proteintech; goat, Piece) at a 1:100000 dilution in a

644 chemiluminescent blocking buffer, at room temperature, for $60 \mathrm{~min}$. Membranes were visualized

645 after a brief incubation in SuperSignalтm West Femto (Thermo Scientific) on the Bio-Rad

646 ChemiDoc MP. Protein expression was normalized to $\alpha$-TUBULIN expression (Cell Signaling)

647 using the ImageLab 4.1 software (Bio-Rad).

648 Live and dead cell counting

649 Live cell number was determined by co-staining cells with Hoechst 33342 (to identify

650 number of nuclei, Life Technologies) and propidium iodide (to identify dead cells, ThermoFisher

651 Scientific). The number of live cells was determined by subtracting the number of propidium 
652 iodide positive cells from the Hoechst 33342 positive cells as identified using the Celigo imaging

653 cytometer (Nexcelcom).

654 Cell cycle analysis

655 For cell cycle analysis, $h$ MPCs were pelleted, washed with ice-cold PBS, re-pelleted and

656 resuspended in PBS then fixed in 3:1 volume:volume 100\% ice-cold ethanol before being stored

657 at $4{ }_{\mathrm{oC}}$ overnight. The following day, cells were pelleted, washed with ice-cold PBS, and

658 resuspended in $400 \mu \mathrm{L}$ PBS containing 2 mM EDTA. Cell suspensions were incubated with 100

$659 \mu \mathrm{L} 10 \mathrm{mg} / \mathrm{mL}$ RNAse A (VWR) for $30 \mathrm{~min}$ at 37oC, to degrade RNA, followed by DNA staining

660 with $50 \mu \mathrm{L}$ of $1 \mathrm{mg} / \mathrm{mL}$ propidium iodide for $30 \mathrm{~min}$, in the dark, at room temperature.

661 Propidium iodide intensity was measured using a flow cytometer (BD Aria Fusion). The

662 percentage of the total population of cells in G1, S-phase, G2 cells were determined using

663 FlowJo's (Becton, Dickinson, and Company) univariate platform.

\section{5-bromo-2'-deoxyuridine (BrdU) incorporation}

To determine the proportion of cells actively synthesizing DNA, $h$ MPCs were pulsed

666 with BrdU for 24 hours. $h$ MPCs were washed with prewarmed PBS before being fixed in ice-

667 cold methanol for $5 \mathrm{~min}$. Cells were washed with PBS before $30 \mathrm{~min}$ of acid hydrolysis and cell-

668 permeabilization in $2 \mathrm{~N} \mathrm{HCl}$ prepared in $0.1 \%$ PBS-Tween20. Cells were washed with PBS

669 before being blocked in 1\% BSA/10\% normal goat serum/0.3 M glycine/0.1\% PBS-Tween20

670 followed by washing in PBS. Fixed and blocked $h$ MPCs were incubated overnight at $4{ }_{\circ} \mathrm{C}$ with an

671 anti-BrdU antibody (1:400 dilution, Biolegend) followed by PBS washes and a 60 min

672 incubation with an Alexa-Fluor 488 conjugated anti-mouse secondary antibody (Invitrogen).

673 Finally, $h$ MPCs were washed with PBS and incubated with Hoechst 33342 before visualization

674 and analysis using the Celigo imaging cytometer (Nexcelcom). 


\section{Glucose uptake}

Glucose uptake was measured based on the detection of 2-deoxyglucose-6-phosphate

677 uptake by a commercially available luminescence-based kit (Glucose Uptake-Glotm Assay,

678 Promega) on a SpectraMax M3 (Molecular Devices). Values were normalized to total cell count

679 obtained from a parallel plate.

680 Stable-Isotope Labeling, Metabolite Extraction, and GC-MS Analysis

For isotopic labeling experiments, cells were cultured in $10 \mathrm{mM}$ [U-13C6]glucose

682 (Cambridge Isotope Laboratories, Inc.) containing either $1000 \mu \mathrm{M}$ serine/glycine or no

683 serine/glycine for $48 \mathrm{~h}$ prior to extraction. A medium exchange was performed after 24 hours.

684 On the day of extraction, polar metabolites were extracted as previously described (Cordes and

685 Metallo, 2019).

687 methoxyamine hydrochloride (Thermo Scientific) in pyridine (incubated for 60 min at $45^{\circ} \mathrm{C}$ ) and

688 followed by $15 \mu \mathrm{L}$ MTBSTFA with $1 \%$ tert-butyldimethylchlorosilane (Regis Technologies)

689 (incubated for $30 \mathrm{~min}$ at $45^{\circ} \mathrm{C}$ ). Polar derivatives were analyzed by GC-MS using a DB-35MS

690 column $(30 \mathrm{~m}$ x $0.25 \mathrm{~mm}$ i.d. $\times 0.25 \mu \mathrm{m})$ installed in an Agilent 7890B GC interfaced with an

691 Agilent 5977B MS with an XTR EI source using the following temperature program: $100^{\circ} \mathrm{C}$

692 initial, increase by $3.5^{\circ} \mathrm{C} / \mathrm{min}$ to $255^{\circ} \mathrm{C}$, increase by $15^{\circ} \mathrm{C} / \mathrm{min}$ to $320^{\circ} \mathrm{C}$ and hold for $3 \mathrm{~min}$.

\section{Glutathione measurements}

694 Total and oxidized (GSSG) glutathione were measured using a commercially available

695 luminescence-based kit (GSH-GSSG Gloтм Assay, Promega) on a SpectraMax M3 (Molecular

696 Devices). The reduced (GSH) to oxidized GSSG ratio was determined by multiplying the GSSG

697 reading by 2 , to account for each mole of oxidized GSSG producing two moles of total 
698 glutathione, subtracting that number from the total glutathione levels and finally, dividing this

699 value by the total GSSG reading. Values were normalized to total cell count obtained from a

700 parallel plate.

701 Reactive oxygen species detection

702 To determine the intracellular level of ROS, $h$ MPCs were pelleted and resuspended in 1

703 mL pre-warmed PBS with CellROX Green Reagent (Invitrogen), a cell-permeable dye which

704 fluoresces green and binds to DNA upon oxidation, at a final concentration of $5 \mu \mathrm{M}$. After a 30

705 min incubation at $37 \mathrm{oC}, h \mathrm{MPCs}$ were washed with PBS before being fixed in $2 \%$

706 paraformaldehyde for $10 \mathrm{~min}$ at room temperature. $h \mathrm{MPCs}$ were again washed with PBS before

707 finally being resuspended in $300 \mu \mathrm{L} 0.5 \mathrm{mM}$ EDTA in PBS and analyzed via flow cytometry

708 (BD Aria Fusion).

709 NAD/NADH measurements

710 The reduced NAD $(\mathrm{NADH})$ to oxidized NAD $(\mathrm{NAD}+)$ ratio was determined in $h \mathrm{MPCs}$

711 via a commercially available luminescence-based kit (NAD/NADH Glotm Assay, Promega)

712 following the manufacturer's instructions. Luminescence values were obtained with a

713 SpectraMax M3 (Molecular Devices) and normalized to total cell count obtained from a parallel

714 plate.

715 Protein synthesis

716 The SUnSET Method (Schmidt et al., 2009) was used to quantify the rate of puromycin

717 incorporation to approximate protein synthesis (Henrich, 2016). $h \mathrm{MPCs}$ were treated with 0.5

$718 \mu \mathrm{g} / \mathrm{mL}$ puromycin (Thermo Fisher) for $30 \mathrm{~min}$ and then immediately harvested in RIPA buffer

719 and protein was isolated as described above. Immunoblotting was performed, as described, using

720 a primary antibody specific for puromycin (Millipore) diluted 1:1000 in a chemiluminescent 
721 blocking buffer overnight, prior to incubation in secondary antibody (mouse, Proteintech) diluted

722 1:100000. $h$ MPCs were incubated in SuperSignalтм West Femto (Thermo Scientific) and imaged

723 on the Bio-Rad ChemiDoc MP. Puromycin expression was normalized to the total protein level

724 in each respective lane as determined by Coomassie staining and imaging on the Bio-Rad

725 ChemiDoc MP using the ImageLab 4.1 software (Bio-Rad).

726 Statistics

727 Statistical analyses were performed in R Studio (Version 1.0.136). For metabolite

728 analysis of whole skeletal muscle tissue, the normalcy of the distribution of each amino acid was

729 assessed by the Shapiro-Wilk test. If data were determined to be normally distributed, they were

730 compared via an unpaired t-test otherwise they were compared by a Mann-Whitney U-test. The

731 correlation between skeletal muscle serine levels and age were determine using a Pearson

732 correlation coefficient. When comparing gene and protein expression between age groups, an

733 unpaired t-test was performed. For cell counting experiments, two-way analysis of variance

734 (ANOVA) was performed with time and treatment being the main factors. A Tukey post hoc test

735 was performed if the interaction term was significant $(\mathrm{P}<0.05)$. For all $h \mathrm{MPC}$ assays, either a

736 paired t-test or a repeated measures ANOVA was employed. 


\section{Acknowledgments}

745 This work was financially supported by a President's Council of Cornell Women Award (to

746 A.T.M), Cornell University Division of Nutritional Sciences funds (to A.T.M), and a Canadian

747 Institutes for Health Research Doctoral Foreign Study Award (to B.J.G), and NIH grant

748 R01CA234245 (to C.M.M.).

750 Author Contributions

751 Conceptualization, B.J.G, P.J.S, and A.E.T..; Methodology, B.J.G, M.S.F., P.J.S., and A.E.T..;

752 Investigation, B.J.G, J.E.B, M.E.G., E.W.L., and M.K.H.; Resources, E.B., P.J.S, M.S.F.,

753 B.D.C., C.M., and A.E.T.; Writing - Original Draft, B.J.G. and A.E.T.; Writing - Review and

754 Editing, B.J.G., J.E.B, M.E.G., E.W.L., M.K.H., P.J.S., M.S.F., B.D.C., C.M.M., and A.E.T.;

755 Supervision, A.E.T.

756

757 Declaration of Interests

758 The authors declare no conflicts of interest.

759

760

761

762

763

764

765

766 


\section{References}

768 Anderson, D.D., and Stover, P.J. (2009). SHMT1 and SHMT2 are functionally redundant in

769 nuclear de novo thymidylate biosynthesis. PLoS One 4.

770 Bergström, J., Fürst, P., Norée, L.O., and Vinnars, E. (2017). Intracellular free amino acid

771 concentration in human muscle tissue. J. Appl. Physiol. 36, 693-697.

772 Blau, H.M., Cosgrove, B.D., and Ho, A.T.V. (2015). The central role of muscle stem cells in 773 regenerative failure with aging. Nat. Med. 21, 854-862.

774 Brack, A.S., Conboy, M.J., Roy, S., Lee, M., Kuo, C.J., Keller, C., and Rando, T.A. (2007).

775 Increased Wnt signaling during aging alters muscle stem cell fate and increases fibrosis. Science

776 (80-. ). 317, 807-810.

777 Caldow, M.K., Ham, D.J., Godeassi, D.P., Chee, A., Lynch, G.S., and Koopman, R. (2016).

778 Glycine supplementation during calorie restriction accelerates fat loss and protects against

779 further muscle loss in obese mice. Clin. Nutr. 35, 1118-1126.

780 Carnwath, J.W., and Shotton, D.M. (1987). Muscular dystrophy in the mdx mouse:

781 Histopathology of the soleus and extensor digitorum longus muscles. J. Neurol. Sci. 80, 39-54.

782 Conboy, I.H., Conboy, M.J., Smythe, G.M., and Rando, T.A. (2003). Notch-Mediated

783 Restoration of Regenerative Potential to Aged Muscle. Science (80-. ). 302, 1575-1577.

784 Conboy, I.M., Conboy, M.J., Wagers, A.J., Girma, E.R., Weissman, I.L., and Rando, T.A.

785 (2005). Rejuvenation of aged progenitor cells by exposure to a young systemic environment.

786 Nature 433, 760-764.

787 Cordes, T., and Metallo, C.M. (2019). Quantifying intermediary metabolism and lipogenesis in

788 cultured mammalian cells using stable isotope tracing and mass spectrometry. In Methods in

789 Molecular Biology, pp. 219-241. 
DeNicola, G.M., Chen, P.H., Mullarky, E., Sudderth, J.A., Hu, Z., Wu, D., Tang, H., Xie, Y.,

Asara, J.M., Huffman, K.E., et al. (2015). NRF2 regulates serine biosynthesis in non-small cell

793 Diehl, F.F., Lewis, C.A., Fiske, B.P., and Vander Heiden, M.G. (2019). Cellular redox state

794 constrains serine synthesis and nucleotide production to impact cell proliferation. Nat. Metab.

795 Dufresne, M.J.P., MacLeod, J., Rogers, J., and Sanwal, B.D. (1976). Serine auxotrophy of myoblasts in primary and secondary culture. Biochem. Biophys. Res. Commun. 70, 1085-1090.

Dunn, W.B., Lin, W., Broadhurst, D., Begley, P., Brown, M., Zelena, E., Vaughan, A.A.,

Halsall, A., Harding, N., Knowles, J.D., et al. (2014). Molecular phenotyping of a UK

population: defining the human serum metabolome. Metabolomics 11, 9-26.

800 Egerman, M.A., Cadena, S.M., Gilbert, J.A., Meyer, A., Nelson, H.N., Swalley, S.E., Mallozzi,

801 C., Jacobi, C., Jennings, L.L., Clay, I., et al. (2015). GDF11 Increases with Age and Inhibits

802 Skeletal Muscle Regeneration. Cell Metab. 22, 164-174.

803 Fazelzadeh, P., Hangelbroek, R.W.J., Tieland, M., De Groot, L.C.P.G.M., Verdijk, L.B., Van

804 Loon, L.J.C., Smilde, A.K., Alves, R.D.A.M., Vervoort, J., Müller, M., et al. (2016). The Muscle

805 Metabolome Differs between Healthy and Frail Older Adults. J. Proteome Res. 15, 499-509.

806 Fulle, S., Di Donna, S., Puglielli, C., Pietrangelo, T., Beccafico, S., Bellomo, R., Protasi, F., and

807 Fanò, G. (2005). Age-dependent imbalance of the antioxidative system in human satellite cells.

808 Exp. Gerontol. 40, 189-197.

809 Gallot, Y.S., Straughn, A.R., Bohnert, K.R., Xiong, G., Hindi, S.M., and Kumar, A. (2018).

810 MyD88 is required for satellite cell-mediated myofiber regeneration in dystrophin-deficient mdx

811 mice. Hum. Mol. Genet. 27, 3449-3463.

812 Gannon, M.C., Nuttall, J.A., and Nuttall, F.Q. (2002). The metabolic response to ingested 
813 glycine. Am. J. Clin. Nutr. 76, 1302-1307.

814 Garofalo, K., Penno, A., Schmidt, B.P., Lee, H.J., Frosch, M.P., Von Eckardstein, A., Brown,

815 R.H., Hornemann, T., and Eichler, F.S. (2011). Oral L-serine supplementation reduces

816 production of neurotoxic deoxysphingolipids in mice and humans with hereditary sensory

817 autonomic neuropathy type 1. J. Clin. Invest. 121, 4735-4745.

818 Gheller, B.J., Blum, J.E., Merritt, E.K., Cummings, B.P., and Thalacker-Mercer, A.E. (2019a).

819 Peptide YY (PYY) is expressed in human skeletal muscle tissue and expanding human muscle

820 progenitor cells. Front. Physiol. 10.

821 Gheller, B.J., Blum, J., Soueid-Baumgarten, S., Bender, E., Cosgrove, B.D., and Thalacker-

822 Mercer, A. (2019b). Isolation, Culture, Characterization, and Differentiation of Human Muscle

823 Progenitor Cells from the Skeletal Muscle Biopsy Procedure. J. Vis. Exp.

824 Ham, D.J., Murphy, K.T., Chee, A., Lynch, G.S., and Koopman, R. (2014). Glycine

825 administration attenuates skeletal muscle wasting in a mouse model of cancer cachexia. Clin.

826 Nutr. 33, 448-458.

827 Ham, D.J., Caldow, M.K., Chhen, V., Chee, A., Wang, X., Proud, C.G., Lynch, G.S., and

828 Koopman, R. (2016). Glycine restores the anabolic response to leucine in a mouse model of

829 acute inflammation. Am. J. Physiol. - Endocrinol. Metab. 310, E970-E981.

830 Ham, D.J., Gardner, A., Kennedy, T.L., Trieu, J., Naim, T., Chee, A., Alves, F.M., Caldow,

831 M.K., Lynch, G.S., and Koopman, R. (2019). Glycine administration attenuates progression of

832 dystrophic pathology in prednisolone-treated dystrophin/utrophin null mice. Sci. Rep. 9, 12982.

833 Hamanaka, R.B., Bennett, B.S., Cullinan, S.B., and Diehl, J.A. (2005). PERK and GCN2

834 contribute to eIF2 $\alpha$ phosphorylation and cell cycle arrest after activation of the unfolded protein

835 response pathway. Mol. Biol. Cell 16, 5493-5501. 
836 Harding, H.P., Zhang, Y., Zeng, H., Novoa, I., Lu, P.D., Calfon, M., Sadri, N., Yun, C., Popko,

837 B., Paules, R., et al. (2003). An integrated stress response regulates amino acid metabolism and

838 resistance to oxidative stress. Mol. Cell 11, 619-633.

839 Henrich, C.J. (2016). A microplate-based nonradioactive protein synthesis assay: Application to

840 TRAIL sensitization by protein synthesis inhibitors. PLoS One.

841 Holcik, M., and Sonenberg, N. (2005). Translational control in stress and apoptosis. Nat. Rev.

842 Mol. Cell Biol. 6, 318-327.

843 Hosios, A.M., Hecht, V.C., Danai, L. V., Johnson, M.O., Rathmell, J.C., Steinhauser, M.L.,

844 Manalis, S.R., and Vander Heiden, M.G. (2016). Amino Acids Rather than Glucose Account for

845 the Majority of Cell Mass in Proliferating Mammalian Cells. Dev. Cell.

846 Houtkooper, R.H., Argmann, C., Houten, S.M., Cant́, C., Jeninga, E.H., Andreux, Ṕeńelope A.,

847 Thomas, C., Doenlen, R., Schoonjans, K., and Auwerx, J. (2011). The metabolic footprint of

848 aging in mice. Sci. Rep. 1.

849 Katsanos, C.S., Kobayashi, H., Sheffield-Moore, M., Aarsland, A., and Wolfe, R.R. (2006). A

850 high proportion of leucine is required for optimal stimulation of the rate of muscle protein

851 synthesis by essential amino acids in the elderly. Am. J. Physiol. - Endocrinol. Metab. 291.

852 Kawase, A., Ito, A., Yamada, A., and Iwaki, M. (2015). Age-related changes in mRNA levels of

853 hepatic transporters, cytochrome P450 and UDP-glucuronosyltransferase in female rats. Eur. J.

854 Drug Metab. Pharmacokinet. 40, 239-244.

855 Kim, D., Pertea, G., Trapnell, C., Pimentel, H., Kelley, R., and Salzberg, S.L. (2013). TopHat2:

856 Accurate alignment of transcriptomes in the presence of insertions, deletions and gene fusions.

857 Genome Biol. 14.

858 Kitzmann, M., Carnac, G., Vandromme, M., Primig, M., Lamb, N.J.C., and Fernandez, A. 
(1998). The muscle regulatory factors MyoD and Myf-5 undergo distinct cell cycle-specific expression in muscle cells. J. Cell Biol.

861 Koopman, R., Caldow, M.K., Ham, D.J., and Lynch, G.S. (2017). Glycine metabolism in skeletal 862 muscle: Implications for metabolic homeostasis. Curr. Opin. Clin. Nutr. Metab. Care 20, 237863242.

864 Kouchiwa, T., Wada, K., Uchiyama, M., Kasezawa, N., Niisato, M., Murakami, H., Fukuyama, 865 K., and Yokogoshi, H. (2012). Age-related changes in serum amino acids concentrations in 866 healthy individuals. Clin. Chem. Lab. Med. 50, 861-870.

867 L’Honoré, A., Commère, P.H., Negroni, E., Pallafacchina, G., Friguet, B., Drouin, J.,

868 Buckingham, M., and Montarras, D. (2018). The role of Pitx2 and Pitx3 in muscle 1 stem cells 869 gives new insights into P38 $\alpha$ MAP kinase and redox regulation of muscle regeneration. Elife 7.

870 Labuschagne, C.F., van den Broek, N.J.F., Mackay, G.M., Vousden, K.H., and Maddocks,

871 O.D.K. (2014). Serine, but not glycine, supports one-carbon metabolism and proliferation of 872 cancer cells. Cell Rep. 7, 1248-1258.

873 Ma, E.H., Bantug, G., Griss, T., Condotta, S., Johnson, R.M., Samborska, B., Mainolfi, N., Suri, 874 V., Guak, H., Balmer, M.L., et al. (2017). Serine Is an Essential Metabolite for Effector T Cell 875 Expansion. Cell Metab. 25, 345-357.

876 Martin, M. (2011). Cutadapt removes adapter sequences from high-throughput sequencing reads.

877 EMBnet.Journal 17, 10.

878 McCarthy, D.J., Chen, Y., and Smyth, G.K. (2012). Differential expression analysis of

879 multifactor RNA-Seq experiments with respect to biological variation. Nucleic Acids Res. 40, $880 \quad 4288-4297$.

881 Menni, C., Kastenmüller, G., Petersen, A.K., Bell, J.T., Psatha, M., Tsai, P.C., Gieger, C., 
Schulz, H., Erte, I., John, S., et al. (2013). Metabolomic markers reveal novel pathways of ageing and early development in human populations. Int. J. Epidemiol. 42, 1111-1119. Minet, A.D., and Gaster, M. (2012). Cultured senescent myoblasts derived from human vastus lateralis exhibit normal mitochondrial ATP synthesis capacities with correlating concomitant ROS production while whole cell ATP production is decreased. Biogerontology 13, 277-285.

Mitchell, W.K., Phillips, B.E., Williams, J.P., Rankin, D., Lund, J.N., Wilkinson, D.J., Smith, K., and Atherton, P.J. (2015). The impact of delivery profile of essential amino acids upon skeletal muscle protein synthesis in older men: Clinical efficacy of pulse vs. bolus supply. Am. J.

Physiol. - Endocrinol. Metab. 309, E450-E457.

891 Pavlidou, T., Rosina, M., Fuoco, C., Gerini, G., Gargioli, C., Castagnoli, L., and Cesareni, G.

892 (2017). Regulation of myoblast differentiation by metabolic perturbations induced by metformin.

893 PLoS One 12.

894 Polymenis, M., and Aramayo, R. (2015). Translate to divide: control of the cell cycle by protein synthesis. Microb. Cell 2, 94-104.

Riddle, E.S., Bender, E.L., and Thalacker-Mercer, A.E. (2018a). Expansion capacity of human

897 muscle progenitor cells differs by age, sex, and metabolic fuel preference. Am. J. Physiol. - Cell Physiol. 315, C643-C652.

899 Riddle, E.S., Bender, E.L., and Thalacker-Mercer, A. (2018b). Transcript profile distinguishes

900 variability in human myogenic progenitor cell expansion capacity. Physiol. Genomics.

901 Rodgers, J.T., King, K.Y., Brett, J.O., Cromie, M.J., Charville, G.W., Maguire, K.K., Brunson,

902 C., Mastey, N., Liu, L., Tsai, C.-R., et al. (2014). mTORC1 controls the adaptive transition of

903 quiescent stem cells from G0 to G(Alert). Nature 509, 393-396.

904 Schmidt, E.K., Clavarino, G., Ceppi, M., and Pierre, P. (2009). SUnSET, a nonradioactive 
method to monitor protein synthesis. Nat. Methods 6, 275-277.

906 Seale, P., Sabourin, L.A., Girgis-Gabardo, A., Mansouri, A., Gruss, P., and Rudnicki, M.A.

907 (2000). Pax7 is required for the specification of myogenic satellite cells. Cell.

908 Sekhar, R. V., Patel, S.G., Guthikonda, A.P., Reid, M., Balasubramanyam, A., Taffet, G.E., and

909 Jahoor, F. (2011). Deficient synthesis of glutathione underlies oxidative stress in aging and can

910 be corrected by dietary cysteine and glycine supplementation. Am. J. Clin. Nutr. 94, 847-853.

911 Sidrauski, C., McGeachy, A.M., Ingolia, N.T., and Walter, P. (2015). The small molecule ISRIB

912 reverses the effects of eIF $2 \alpha$ phosphorylation on translation and stress granule assembly. Elife

9132015.

914 Sinha, M., Jang, Y.C., Oh, J., Khong, D., Wu, E.Y., Manohar, R., Miller, C., Regalado, S.G.,

915 Loffredo, F.S., Pancoast, J.R., et al. (2014). Restoring systemic GDF11 levels reverses age-

916 related dysfunction in mouse skeletal muscle. Science (80-. ).

917 Sousa-Victor, P., Gutarra, S., García-Prat, L., Rodriguez-Ubreva, J., Ortet, L., Ruiz-Bonilla, V.,

918 Jardí, M., Ballestar, E., González, S., Serrano, A.L., et al. (2014). Geriatric muscle stem cells

919 switch reversible quiescence into senescence. Nature 506, 316-321.

920 Sun, K., Wu, Z., Ji, Y., and Wu, G. (2016). Glycine Regulates Protein Turnover by Activating

921 Protein Kinase B/Mammalian Target of Rapamycin and by Inhibiting MuRF1 and Atrogin-1

922 Gene Expression in C2C12 Myoblasts. J. Nutr. 146, 2461-2467.

923 Wallace, M., Green, C.R., Roberts, L.S., Lee, Y.M., McCarville, J.L., Sanchez-Gurmaches, J.,

924 Meurs, N., Gengatharan, J.M., Hover, J.D., Phillips, S.A., et al. (2018). Enzyme promiscuity

925 drives branched-chain fatty acid synthesis in adipose tissues. Nat. Chem. Biol. 14, 1021-1031.

926 Woeller, C.F., Anderson, D.D., Szebenyi, D.M.E., and Stover, P.J. (2007). Evidence for small

927 ubiquitin-like modifier-dependent nuclear import of the thymidylate biosynthesis pathway. J. 
928 Biol. Chem. 282, 17623-17631.

929 Xu, X., Wilschut, K.J., Kouklis, G., Tian, H., Hesse, R., Garland, C., Sbitany, H., Hansen, S.,

930 Seth, R., Knott, P.D., et al. (2015). Human Satellite Cell Transplantation and Regeneration from

931 Diverse Skeletal Muscles. Stem Cell Reports 5, 419-434.

932 Zismanov, V., Chichkov, V., Colangelo, V., Jamet, S., Wang, S., Syme, A., Koromilas, A.E., and

933 Crist, C. (2016). Phosphorylation of eIF2 $\alpha$ is a Translational Control Mechanism Regulating

934 Muscle Stem Cell Quiescence and Self-Renewal. Cell Stem Cell 18, 79-90.

935

936

937

938

939

940

941

942

943

944

945

946 


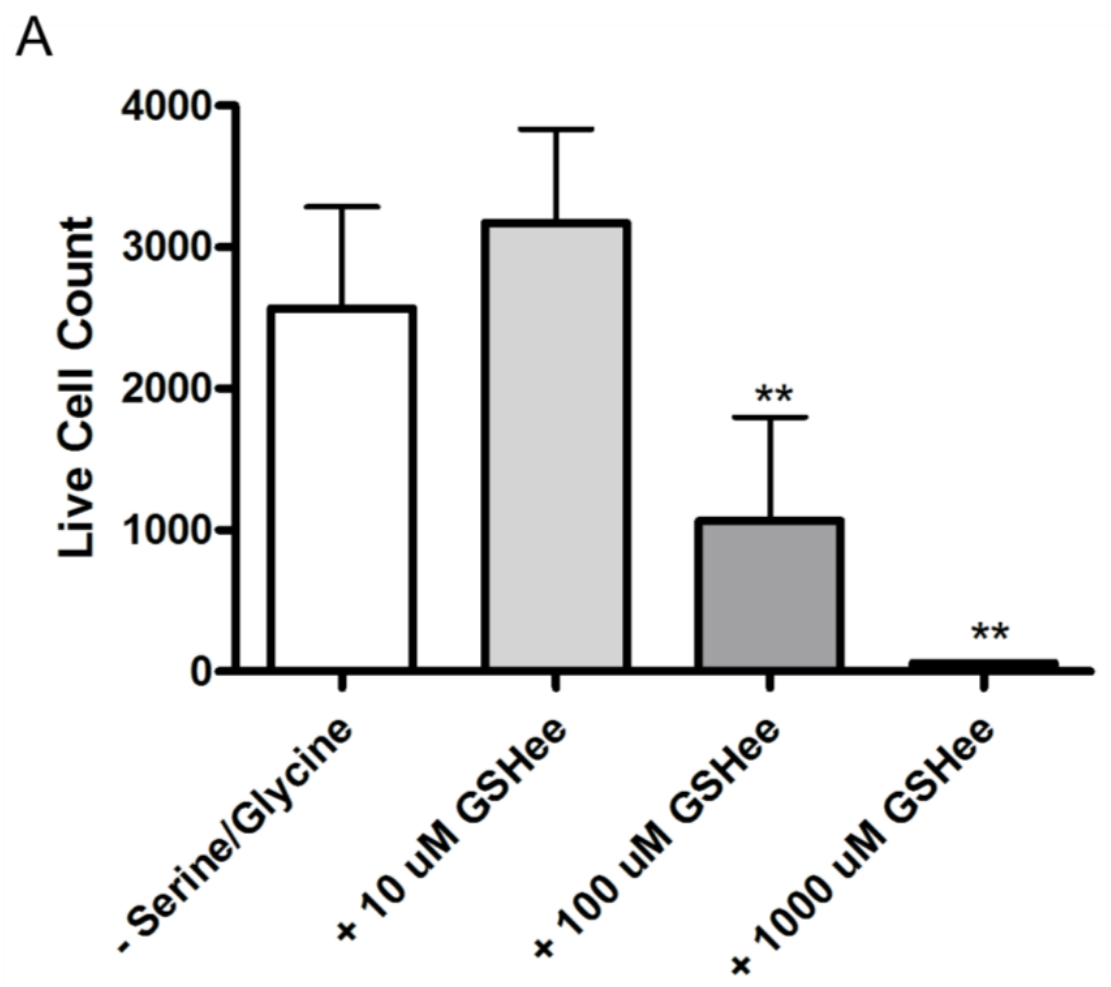

948 Figure S1. Glutathione ethyl ester is toxic to $h$ MPCs at high doses

A) Live cell count after 5 days of GSHee (glutathione ethyl ester) supplementation in serine/glycine restricted media.

952 All experiments were repeated with $h \mathrm{MPCs}$ derived from the same 5 donors. $* * \mathrm{P}<0.01$ relative

953 to serine/glycine restricted control. Data are expressed as mean $\pm \mathrm{SD}$. 
A

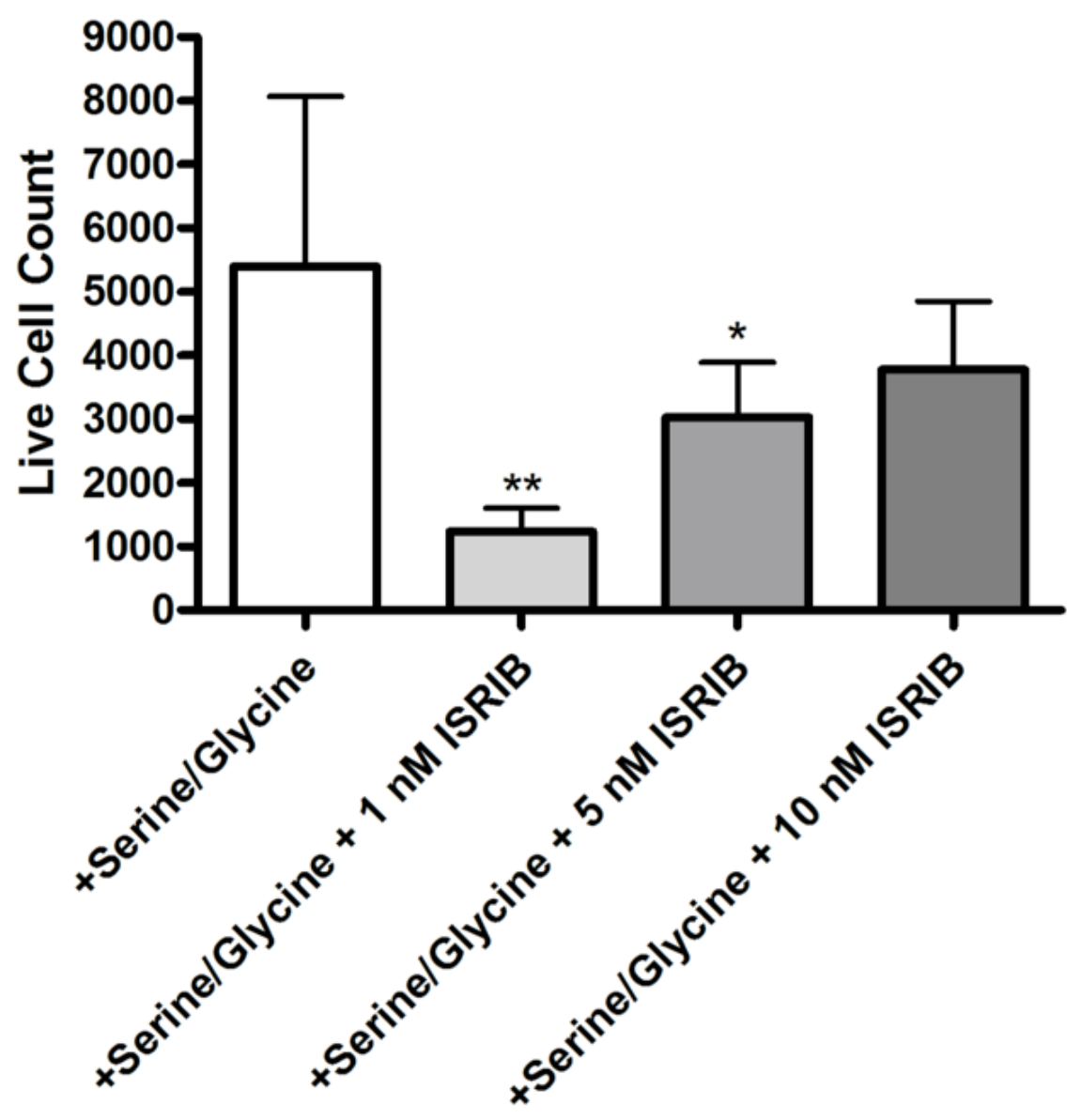

963 Figure S2. ISRIB reduces $h \mathrm{MPC}$ number in the presence of serine/glycine

A) Live cell count after 5 days of ISRIB supplementation in serine/glycine replete media.

966 All experiments were repeated with $h \mathrm{MPCs}$ derived from the same 5 donors. $* * \mathrm{P}<0.01$,

$967 * * \mathrm{P}<0.01$ relative to serine/glycine replete control. Data are expressed as mean $\pm \mathrm{SD}$. 
bioRxiv preprint doi: https://doi.org/10.1101/833798; this version posted November 7, 2019. The copyright holder for this preprint (which was not certified by peer review) is the author/funder, who has granted bioRxiv a license to display the preprint in perpetuity. It is made available under aCC-BY-NC-ND 4.0 International license.

\section{Supplementary Tables}

971 Supplementary Table 1. List of Differentially Expressed Genes in $h$ MPCs Cultured in

972 Serine/Glycine Replete and Serine/Glycine Restricted Media 